\title{
The dystroglycan receptor maintains glioma stem cells in the vascular niche
}

\author{
Bryan W. Day ${ }^{1,2,3}$ - Justin D. Lathia ${ }^{4} \cdot$ Zara C. Bruce $^{1} \cdot$ Rochelle C. J. D'Souza $^{1} \cdot$ Ulrich Baumgartner $^{1}$. \\ Kathleen S. Ensbey ${ }^{1} \cdot$ Yi Chieh Lim ${ }^{1} \cdot$ Brett W. Stringer ${ }^{1}$. Seçkin Akgüll ${ }^{1}$ Carolin Offenhäuser ${ }^{1} \cdot$ Yuchen Li $^{1}$.

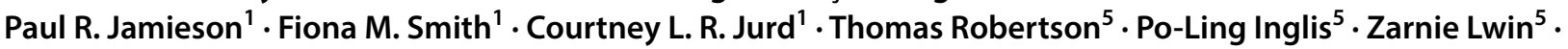 \\ Rosalind L. Jeffree ${ }^{5} \cdot$ Terrance G. Johns $^{6} \cdot$ Krishna P. L. Bhat $^{7}$. Jeremy N. Rich ${ }^{8} \cdot$ Kevin P. Campbell9,10 $^{9}$ \\ Andrew W. Boyd ${ }^{1,3}$
}

Received: 9 May 2019 / Revised: 21 August 2019 / Accepted: 22 August 2019 / Published online: 28 August 2019

(c) The Author(s) 2019

\begin{abstract}
Glioblastomas (GBMs) are malignant central nervous system (CNS) neoplasms with a very poor prognosis. They display cellular hierarchies containing self-renewing tumourigenic glioma stem cells (GSCs) in a complex heterogeneous microenvironment. One proposed GSC niche is the extracellular matrix (ECM)-rich perivascular bed of the tumour. Here, we report that the ECM binding dystroglycan (DG) receptor is expressed and functionally glycosylated on GSCs residing in the perivascular niche. Glycosylated $\alpha \mathrm{DG}$ is highly expressed and functional on the most aggressive mesenchymal-like (MES-like) GBM tumour compartment. Furthermore, we found that DG acts to maintain an MES-like state via tight control of MAPK activation. Antibody-based blockade of $\alpha$ DG induces robust ERK-mediated differentiation leading to reduced GSC potential. DG was shown to be required for tumour initiation in MES-like GBM, with constitutive loss significantly delaying or preventing tumourigenic potential in-vivo. These findings reveal a central role of the DG receptor, not only as a structural element, but also as a critical factor promoting MES-like GBM and the maintenance of GSCs residing in the perivascular niche.
\end{abstract}

Keywords Glioblastoma (GBM) · Dystroglycan (DG) · MES-like GBM · EphA3 · Integrin- $\alpha 6 \cdot$ Glioma stem cell (GSC) commitment $\cdot$ Perivascular niche $\cdot$ MAPK signalling

\section{Introduction}

Electronic supplementary material The online version of this article (https://doi.org/10.1007/s00401-019-02069-x) contains supplementary material, which is available to authorized users.

\section{Bryan W. Day}

Bryan.Day@qimrberghofer.edu.au

1 Department of Cell and Molecular Biology, Sid Faithfull Brain Cancer Laboratory, QIMR Berghofer Medical Research Institute, Brisbane, QLD 4006, Australia

2 Faculty of Health, Queensland University of Technology, Brisbane 4059, Australia

3 Faculty of Medicine, The University of Queensland, Brisbane 4072, Australia

4 Cleveland Clinic, Lerner College of Medicine, Case Western Reserve University, Cleveland, OH 44195, USA

5 Royal Brisbane and Women's Hospital, Brisbane, QLD 4006, Australia
Glioma stem cells (GSCs) have been shown to reside in both the necrotic and perivascular regions of the tumour, where glioblastoma (GBM) cells adopt a more stem

6 Telethon Kids Institute, Perth, WA 6009, Australia

7 Department of Translational Molecular Pathology, The University of Texas, MD Anderson Cancer Center, Houston, TX 77030, USA

8 Medicine Department, University of California, La Jolla, San Diego, CA 92093-0021, USA

9 Department of Molecular Physiology and Biophysics, Roy J. and Lucille A. Carver College of Medicine, Howard Hughes Medical Institute, University of Iowa, Iowa City, IA 52242, USA

10 Department of Neurology, Roy J. and Lucille A. Carver College of Medicine, Howard Hughes Medical Institute, University of Iowa, Iowa City, IA 52242, USA 
cell-like phenotype $[3,9,11]$. Recently, single-cell RNA sequencing studies have identified four GBM cellular states (MES-like, NPC-like, OPC-like and AC-like) that exist in varying degrees within single tumours [46]. This seminal study highlights the diversity and heterogeneity present within these aggressive tumours and provides a framework for better understanding the genetic diversity, plasticity and influence of the tumour microenvironment (TME) in GBM.

Extracellular matrix (ECM) proteins and basement membrane (BM) formation are key structural components required to support the TME in GBM [25]. The dystrophin-glycoprotein complex (DGC) is a large transmembrane oligomeric complex of sarcolemmal proteins and glycoproteins. A central component of the DGC is the dystroglycan (DG) receptor. DG is an ECM binding receptor best known for its function in bridging the ECM and the cytoskeleton in skeletal myocytes [30]. The DG receptor comprises two non-covalently linked $\alpha$ and $\beta$ subunits. $\alpha \mathrm{DG}$, the extracellular component, is highly glycosylated. Laminin binds a glycan (carbohydrate) structure attached to $\alpha \mathrm{DG}$ and this interaction is critical in regulating ECM attachment. $\beta \mathrm{DG}$, the membrane spanning component, primarily regulates dystrophin attachment to F-actin cables within the cell $[18,19,32]$. Dysregulation of $\alpha$ DG glycosylation or DG loss leads to various forms of muscular dystrophy, the most well-known being Duchenne muscular dystrophy (DMD) $[17,20]$. DG has also been shown to be critical for brain development with receptor dysregulation leading to a number of structural and functional brain defects $[43,44]$. In comparison to skeletal muscle function, less is known about the role of the DGC in adult brain. DG has been linked to blood-brain barrier (BBB) function and is present on the perivascular end feet of astrocytes, where it mediates cell adhesion to vascular ECM proteins [29, 41, 47, 48]. DG also has an established role in regulating oligodendrocyte differentiation and function $[2,12,22,35]$. More recently, Colognato and colleagues revealed that DG is present in the subventricular zone (SVZ) and regulates neural stem and progenitor cell proliferation via suppression of Notch signalling in the postnatal brain [39].

Eph receptor tyrosine kinases and integrin family receptors have been well described as having functional roles in GSC niche formation and maintenance. Eph receptors were first described during development and have been shown to be functionally over expressed in a wide variety of human cancers $[7,31,51]$. Our previous work and the findings of others have shown that a particular family member, EphA3, is significantly elevated in MES-like GBM, is most highly expressed on GSCs, particularly in perivascular regions, and is significantly elevated in recurrent disease [13, 24, 54]. Moreover, EphA3 has been shown to be over expressed and functional on mesenchymal stromal cells in the TME of human cancers [58]. Recently, we have shown that EphA3 can be effectively targeted in GBM animal models using pay-loaded antibody therapeutic strategies [50]. Integrin receptors, particularly integrin $\alpha 6$ is also expressed on GSCs in the perivascular niche and functions to promote tumourigenesis [11,34].

The role of $\alpha \mathrm{DG}$ in GSC commitment and its contribution to GBM cellular states is yet to be elucidated. Here, we identify a central role of the $\alpha \mathrm{DG}$ receptor in promoting a GBM MES-like state and maintenance of GSCs in the vascular niche via tight regulation of ERK signalling. Our findings indicate that $\alpha \mathrm{DG}$ is functionally glycosylated and cooperates with EphA3 and integrin $\alpha 6$ receptors to mediate an MES-like state and further acts to anchor GSCs residing in perivascular tumour regions.

\section{Materials and methods}

\section{Experimental model and subject details}

\section{Human samples}

Human brain cancer specimens were collected from the Royal Brisbane and Women's Hospital (RBWH) under Human Ethics approved project HREC/17/QRBW/577: Novel Therapies for Brain Cancer. Specimens were collected immediately following resection and processed for analysis at QIMR Berghofer laboratories.

\section{Primary cell cultures}

We have developed a characterised GBM patient-derived cell line resource, data is publicly available from Q-Cell https:// www.qimrberghofer.edu.au/q-cell/ [14, 57] GBM lines are maintained as glioma neural stem cell (GNS) cultures [52] or as neurosphere cultures using StemPro NSC SFM (Invitrogen) as per manufacturer's guidelines. U251-MG GBM cells were obtained from the ATCC and cultured as neurospheres as described above.

\section{Animal studies}

All mice experiments were performed according to the National Health and Medical Research Council (2013) Australian code for the care and use of animals for scientific purposes, under experimental protocols approved by the QIMR Berghofer Animal Ethics Committee. 


\section{Animal strain}

For intracranial (orthotopic) xenograft studies, five week-old female NOD/SCID (NOD.CB17-Prkdc scid/Arc, animals were sourced from the Animal Resources Centre (ARC), Canning Vale Western Australia.

\section{Orthotopic engraftment}

Primary lines derived from human GBM specimens were transduced with lentiviral vectors expressing multiple combined DAG1 shRNA targeting sequences, or expressing a non-targeting control shRNA. Cells were counted $\left(1.6 \times 10^{4}\right.$ cells for WK1 GNS - 4 animals per group; $1.5 \times 10^{5}$ cells for JK2 GNS -7 animals per group) and engrafted intracranially into the right striatum $(0.8 \mathrm{~mm}$ lateral of the midline, $1.6 \mathrm{~mm}$ caudal to the bregma, at a depth of $3 \mathrm{~mm}$ ) using a small animal stereotactic device. Mice were given analgesia (Meloxicam (Ilium) $5 \mathrm{mg} / \mathrm{kg}$, delivered subcutaneously) $30 \mathrm{~min}$ prior to surgery and again the following day. Mice were monitored daily for signs of illness or tumour burden, as per our ethical guidelines, animal monitoring criteria and scoring. At endpoint, animals were euthanised by cervical dislocation. Brains were collected and fixed in $10 \%$ neutral - buffered formalin for $24 \mathrm{~h}$, transferred to $70 \%$ ethanol, then subsequently embedded in paraffin. Sections were cut $(4 \mu \mathrm{m})$ and stained for $\mathrm{H} \& \mathrm{E}$ according to common methods, using a Leica ST5010 Autostainer XL and Leica CV5030 Fully Automated Glass Coverslipper (both Leica Biosystems).

\section{Method details}

\section{RNA isolation and real-time PCR}

Total cellular RNA was isolated from tissue or cell lines using TRIzol reagent (Thermo Scientific). RNA was DNase treated using RQ1 RNase-Free DNase (Promega), then first strand cDNA was synthesised using random hexamers (Random Primer 6, New England BioLabs) SuperScript III Reverse Transcriptase (Thermo Scientific), and dNTPs (Promega). Real-time PCR was performed using a Viia 7 Real-Time PCR System and SYBR-Green PCR Master Mix (both Thermo Scientific). Results were normalised to $\beta$-actin $(A C T B)$, with expression represented as copy number per $1000 \beta$-actin. Sequences for gene-specific primer sets were as in Table 1:
Table 1 Gene-specific primer sets

\begin{tabular}{llll}
\hline$\#$ & Primer & Forward 5'-3' & Reverse 5'-3' \\
\hline 1 & ACTB $(\beta$-actin) & CACACTGTGCCCATCTACGA & GTGGTGGTGAAGCTGTAGCC \\
2 & DAG1 & AGGCAGATCCATGCTACACC & AGGATCCCTGACTGGAGGAG \\
3 & $I T G A 6 A$ & CCACATATCACAAGGCTGAG & CACTGTCATCGTACCTAGAG \\
4 & $I T G A 6 B$ & ATTCTCGCTGGGATCTTGATG & GATCCTTACAGCATGGTATCGG \\
5 & CDH1 & GGCTGATACTGACCCCACAG & CGTACATGTCAGCCAGCTTC \\
6 & CDH2 & CCTTGATCTGATGTTTGTGG & CCTGGTCTTCTTCTCCA \\
7 & SNAI2 & TGTTGCAGTGAGGGCAAGAA & GACCCTGGTTGCTTCAAGGA \\
8 & SNAII & ACCACTATGCCGCGCTCTT & GGTCGTAGGGCTGCTGGAA \\
9 & TWIST1 & GGAGTCCGCAGTCTTACGAG & TCTGGAGGACCTGGTAGAGG \\
10 & VEGFA & AGGGCAGAATCATCACGAAGT & AGGGTCTCGATTGGATGGCA \\
11 & BMI1 & TGCTGGAGAACTGGAAAGTG & GATGAGGAGACTGCACTGGA \\
12 & VIM & AGATGGCCCTTGACATTGAG & CCAGAGGGAGTGAATCCAGA \\
13 & EPHA3 & GATGTTGGTGCTTGTGTTGC & GTGTCTGGAAACATAGCCAGATT \\
14 & EPHA2 & GGGACCTGATGCAGAACATC & AGTTGGTGCGGAGCCAGT \\
15 & FUT4 (CD15) & TACGATTTGTGCCCCGGCGC & GATAGACCGCGGGGTTGCGG \\
16 & PROM1 (CD133) & GCCACCGCTCTAGATACTGC & TCGTACACGTCCTCCGAATC \\
17 & $I T G A 6$ (CD49f) & TCATGGATCTGCAAATGGAA & AGGGAACCAACAGCAACATC \\
18 & SOX2 & GCGAACCATCTCTGTGGTCT & GGAAAGTTGGGATCGAACAA \\
19 & TUBB 3 (BIII-tubulin) & AACGAGGCCTCTTCTCACAA & GGCCTGAAGAGATGTCCAAA \\
20 & OLIG2 & AACAGTTTGGGTTATTTGGG & GGAGGAGTTTACCATTTGTG \\
21 & ESRP1 & GGGAGTTCGCCACAGATATTC & AGCCATAAATGCTCTGTCCG \\
\hline
\end{tabular}

All primers were against human sequences 


\section{Cellular fractionation and western blotting}

Total cellular protein was isolated using $8 \mathrm{M}$ Urea with phosphatase and protease inhibitors. Membrane-and-cytoplasmic protein fractions was isolated using a Mem-PER Plus Membrane Protein Extraction kit (Life Technologies). Equal amounts of protein were loaded, separated by SDS/PAGE and immunoblotted using standard methods. For Western blotting, we used $\alpha$ DG (Millipore IIH6C4, 1:1000), EphA2 (CST 6997, 1:1,000) and EphA3 (Invitrogen, 373,200, 1:1,000), ERK1/2 (CST 4695, 1:1,000), and p-ERK1/2 (CST 4370, 1:1,000). $\beta$-Actin was used as a loading control (CST 3700, 1:2,000).

\section{Immunohistochemistry}

Immunohistochemistry experiments were performed using OCT-embedded frozen specimens from patient brain tumours. $6 \mu \mathrm{m}$ sections were cut, fixed in a solution of 2:1 acetone:ethanol for $5 \mathrm{~min}$, incubated in 3\% hydrogen peroxide (Chem-supply) for $10 \mathrm{~min}$ to block endogenous peroxidase activity, and incubated in Background Sniper (Biocare Medical) for $30 \mathrm{~min}$ to block non-specific binding, then incubated with the following primary antibodies at $4{ }^{\circ} \mathrm{C}$ overnight: Vimentin, clone V9 (DAKO M0725, 1:400), 1F7 (in-house anti-EphA2, 1:75), IIIA4 (in-house anti-EphA3, 1:50), $\alpha$-dystroglycan/LARGE-glycan, clone VIA4-1 (Merck Millipore 05-298, 1:75), $\beta$-dystroglycan (B-4) (Santa Cruz Biotechnology sc-165997, 1:100), CD31 (M-20) (Santa Cruz Biotechnology sc-1506 1:50), GFAP, clone GA-5 (Biocare Medical CM 065, 1:500), CDW49f, clone 4F10 (Merck Millipore BCL458, 1:25), Ki-67 (Abcam ab66155, 1:300), Caspase-3 (Biocare Medical CP 229, 1:80), Phospho-p44/42 MAPK (Erk1/2) (Thr202/Tyr204) (Cell Signalling Technology $4370 \mathrm{~s}, 1: 400$ ), following by incubation with a MACH1 or MACH2 HRP Polymer Detection (Biocare Medical), according to the manufacturers instruction, together with the 3,3'-Diaminobenzidine (DAB) Chromogen Kit (Biocare Medical), for detection. Sections, where then counterstained (Mayer's Haematoxylin), dehydrated, cleared and coverslipped, using a Leica ST5010 Autostainer XL and Leica CV5030 Fully Automated Glass Coverslipper (both Leica Biosystems).

\section{Flow cytometry}

Expression was analysed using primary antibodies with the following specificities: $\alpha$-Dystroglycan (EMD Millipore, IIH6C4, 1:100), EphA2 (in-house, 1F7, 1:100), EphA3 (in-house, IIIA4, 1:100), CD133 (Miltenyi Biotec, AC133, 1:20), CD49f (Abcam, GoH3, 1:200), CD29 (Abcam, EP16895, 1:100) and CD15 (Abcam, SP159, 1:200). IgG1 and IgM antibodies (Abcam, 1:100) were used to indicate background staining. Cells were washed twice in PBS and blocked for $20 \mathrm{~min}$ in PBS supplemented with 1\% BSA (Sigma). After blocking, cells were incubated with primary antibodies for $20 \mathrm{~min}$ at room temperature (RT). Washed cells were then incubated for $20 \mathrm{~min}$ at $4{ }^{\circ} \mathrm{C}$ in the dark with secondary antibodies Anti-Mouse IgM Alexa Fluor 488 (Abcam, 1:2000), Anti-Rabbit Alexa Fluor 647 (Abcam, 1:2000) and/or Anti-Rat Alexa Fluor 647 (Abcam, 1:2000). Before analysis cells were washed in blocking solution to remove any unbound antibody conjugates. Between 20,000 and 50,000 total events were examined using an LSRFortessa (BD) with data analysed using FACSDiva (BD) software. Live cells were gated using propidium iodide (Sigma, $50 \mu \mathrm{g} / \mathrm{ml}$ ) staining.

\section{Amnis analysis}

The flow cytometry procedure was repeated for GBM cell lines, as described above. Samples were then run on an ImageStream ${ }^{\mathrm{x}}$. Briefly, 5,000 events were collected for each sample and single color controls used to create a compensation matrix to correct for spectral overlap. All data were then analyzed using IDEA software (Amnis Corporation, Seattle, WA, USA).

\section{Immunofluorescence}

\section{Perivascular tissue staining}

Dual IF experiments were performed using OCT-embedded frozen specimens from patient GBM tumours cut, fixed, incubated in hydrogen peroxide and Background Sniper as described under IHC. Sections were incubated with $\alpha$-dystroglycan antibody (Abcam ab106110, 1:50, $4{ }^{\circ} \mathrm{C}$ overnight) and goat anti-mouse AF488 (1:300 RT for $1 \mathrm{~h}$ ) followed by purified IgG mouse Fab fragments (1:4000 RT for $10 \mathrm{~min}$ ) and rodent block Fab fragment 5 (1:50 RT for $1 \mathrm{~h})$ to block any free mouse antibody. The second staining was performed with CD31/PECAM, Clone -JC70A (Dako M0823, 1:30, RT 2 h), goat anti-mouse AF647 (1:300 RT $1 \mathrm{~h}$ ) and coverslipped with DAKO fluorescent mounting media and visualized using a Zeiss confocal microscope.

\section{Differentiation marker staining}

Single cells were suspended in StemPro NSC SFM (Invitrogen) and seeded in 24-well plates containing sterile coverslips. Cells were then treated with $\alpha$-Dystroglycan inhibiting antibody (EMD Millipore, IIH6C4, 1:100) or an IgM control antibody (Mo1, in-house, 1:100) for $24 \mathrm{~h}$. After treatment, adherent and tumoursphere cultures were fixed in $4 \%$ PFA for $15 \mathrm{~min}$ at RT. Cells were then blocked and expression of extracellular proteins $\alpha$-Dystroglycan, EphA3 and EphA2 
were analysed as previously described. Expression of differentiation markers $\beta$ III-tubulin (Promega G712A, 1:100), GFAP (DAKO 20,334, 1:100) and myelin basic protein (Sigma M3821, 1:100) were analysed by permeabilising fixed cultures in $0.25 \%$ Triton $\mathrm{X}-100$ for $10 \mathrm{~min}$ at $4{ }^{\circ} \mathrm{C}$.

\section{Nuclear ERK translocation}

Single cells were seeded on coverslips in a 24-well plate and growth factor starved overnight. Cells were then treated with $\alpha$-Dystroglycan inhibiting antibody (EMD Millipore, IIH6C4, 1:100) or an IgM control (Mo1, in-house, 1:100) for $24 \mathrm{~h}$ prior to fixing and permeabilisation, as described. A control well treated with FBS (Gibco, 2\%) was also included. Expression of ERK translocation was observed using the antibody phosphorylated-ERK (Cell Signalling, D13.14.4E, 1:200).

\section{DAG1 knockdown validation}

Single cells were seeded on coverslips coated in Matrigel (Corning, 1:200) and $\alpha$-Dystroglycan expression was analysed as previously described.

\section{a-Dystroglycan antibody blockade}

Single cells were suspended in StemPro NSC SFM (Invitrogen) without growth factors and seeded in 6-well plates $\left(5 \times 10^{4}\right.$ per well $)$ in triplicate and treated with $\alpha$-Dystroglycan inhibiting antibody (EMD Millipore, IIH6 $\mathrm{C} 4,1: 100,50 \mu \mathrm{g} / \mathrm{ml}$ ) or an IgM control (Mo1, in-house, $1: 100,50 \mu \mathrm{g} / \mathrm{ml}$ ). After 7 days, adherent and neurosphere cultures were collected and dissociated using accutase, proliferation was calculated by direct cell counting using a haemocytometer.

\section{IncuCyte}

Single GBM cells $\left(1 \times 10^{3}\right)$ were plated onto individual wells (96-well format) for $16 \mathrm{~h}$ prior to experimentation. Cells were treated with $\alpha$-Dystroglycan inhibiting antibody (EMD Millipore, IIH6C4, 1:100, $50 \mu \mathrm{g} / \mathrm{ml}$ ) or an IgM control (Mo1, 1:100, $50 \mu \mathrm{g} / \mathrm{ml}$ ). The Incucyte system (Essen Instruments) was employed to quantitate cell adhesion, as a surrogate read out for differentiation, in real time.

\section{Apoptosis}

Apoptosis and viability was assessed using the ApoToxGlo Triplex assay (Promega) as described [4]. Cleaved caspase $3 / 7$ activity and cell viability was assessed $48 \mathrm{~h}$ post IIH6 treatment, $7.5 \mathrm{mg} / \mathrm{mL}$ cisplatin treatment was used as a positive control. Results are shown as caspase $3 / 7$ activity normalised to cell viability relative to $\operatorname{IgM}$ control $(n=3)$.

\section{Cell culture and transduction}

Target cells were plated on Matrigel-coated (Corning, 1:200) plates in StemPro NSC SFM (Invitrogen) at 50\% confluency $24 \mathrm{~h}$ prior to viral infection. The next day, plating media was removed and polybrene (Santa Cruz, $5 \mu \mathrm{g} / \mathrm{ml}$ ) added, followed by the addition of the Lentiviral Particles $\alpha / \beta$-Dystroglycan shRNA (Santa Cruz, sc-43488-V, $20 \mu \mathrm{l} /$ $\mathrm{ml}$ ) and control shRNA (Santa Cruz, sc-108080, $20 \mu \mathrm{l} / \mathrm{ml}$ ). $24 \mathrm{~h}$ following transduction, fresh media was added and cells underwent puromycin (Gibco, $0.3 \mu \mathrm{l} / \mathrm{ml}$ ) selection.

\section{MAPK activation studies}

\section{CD49f KD and mAb-blocking studies}

CD49f was down regulated using previous validated integrin $\alpha 6$ shRNA sequences compared to a control shRNA [34]. Target cells were plated at $50 \%$ confluency $24 \mathrm{~h}$ prior to transfection. The next day, plating media was removed and cells were transfected using a FuGENE ${ }^{\circledR} \mathrm{HD}$ :DNA ratio of 3.0:1 (Promega). FACSAria IIIu (BD) was used to select positive clones based on GFP expression. Expression KD was confirmed via flow cytometry using CD49f (Abcam, GoH3, 1:200). Dissociated cells were seeded in 24-well plates and treated with $\alpha$-Dystroglycan inhibiting antibody (EMD Millipore, IIH6C4, 1:100) or an IgM control (Mo1, in-house, 1:100).

Single cells were seeded in 6-well plates and growth factor starved overnight. Pre-blocked cells were then treated with CD49f (Invitrogen, eBioGoH3, $10 \mu \mathrm{g} / \mathrm{ml}$ ) $24 \mathrm{~h}$ prior to treatment with $\alpha$-Dystroglycan inhibiting antibody (EMD Millipore, IIH6C4, 1:100) or an IgM control (Mo1, in-house, 1:100). After $3 \mathrm{~h}$ incubation cells were collected and pERK (Cell Signalling, D13.14.4E, 1:2000) and total ERK (Cell Signalling, 137F5, 1:1000) expression was analysed via western blot.

\section{EGFR inhibitor studies}

Single cells were seeded in 24-well plates and growth factor starved overnight. Cells were then treated with Erlotinib $(2 \mu \mathrm{M})$ or Gefitinib $(2 \mu \mathrm{M}) 24 \mathrm{~h}$ prior to treatment with $\alpha$-Dystroglycan inhibiting antibody (EMD Millipore, IIH6C4, 1:100) or an IgM control (Mo1, in-house, 1:100).

\section{Quantification and statistical analysis}

In-vivo experiments-sample size or replicate number (designated as " $n$ ") for each experiment are indicated in 

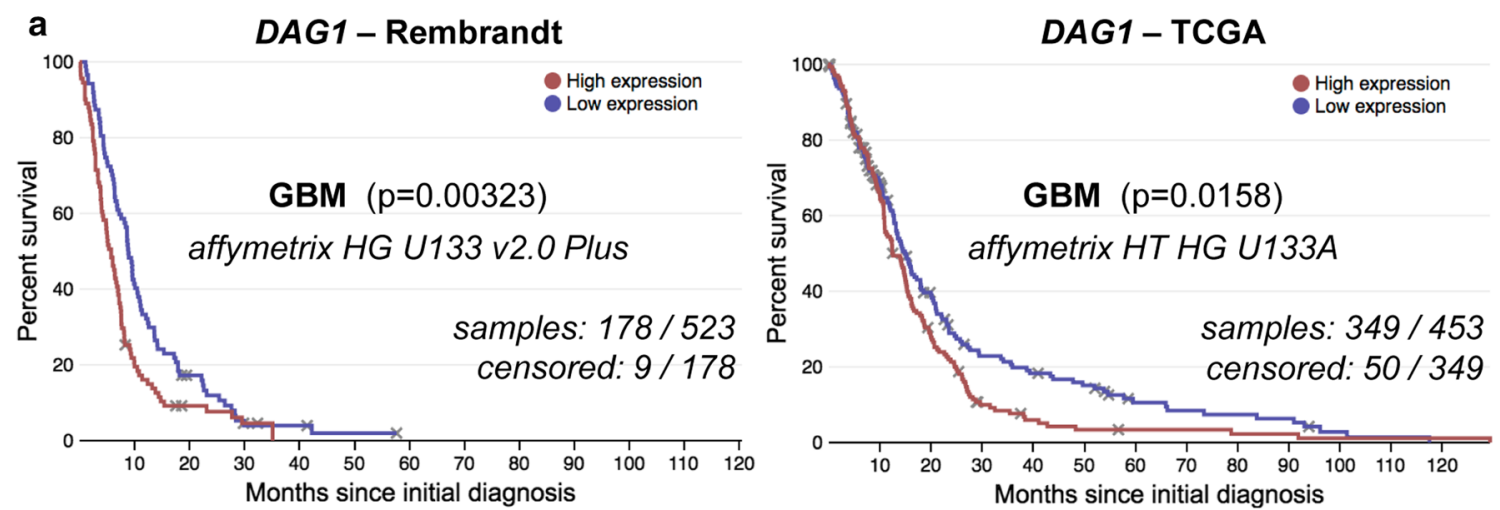

b GBM patient tissue

C
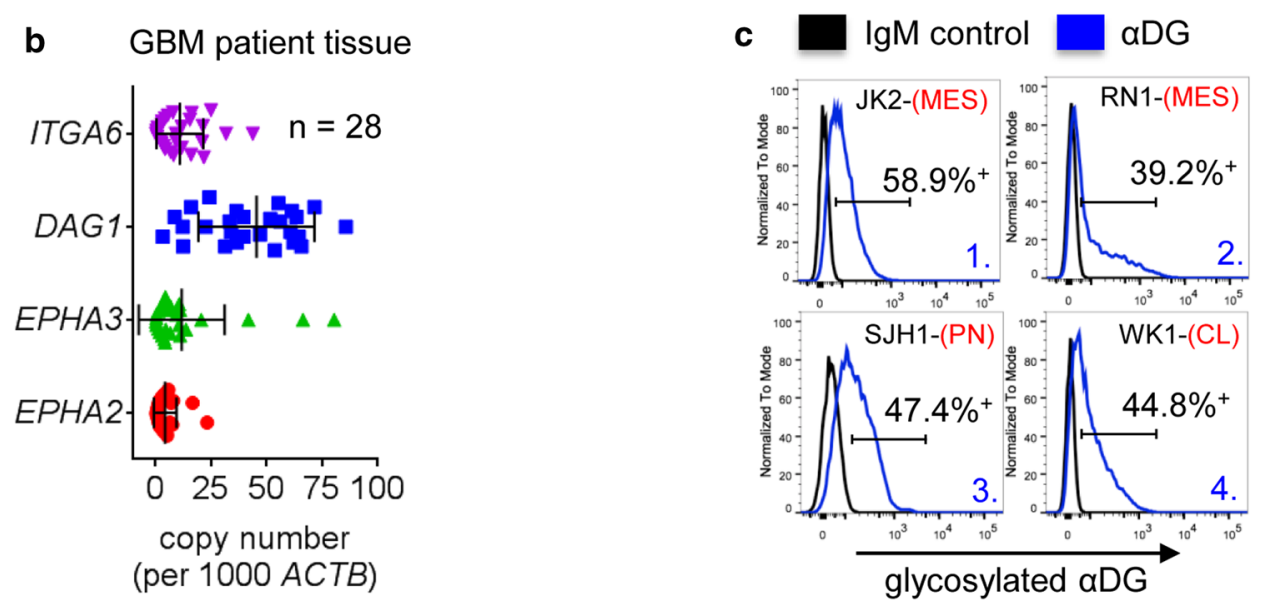

d

e cytoplasmic membrane
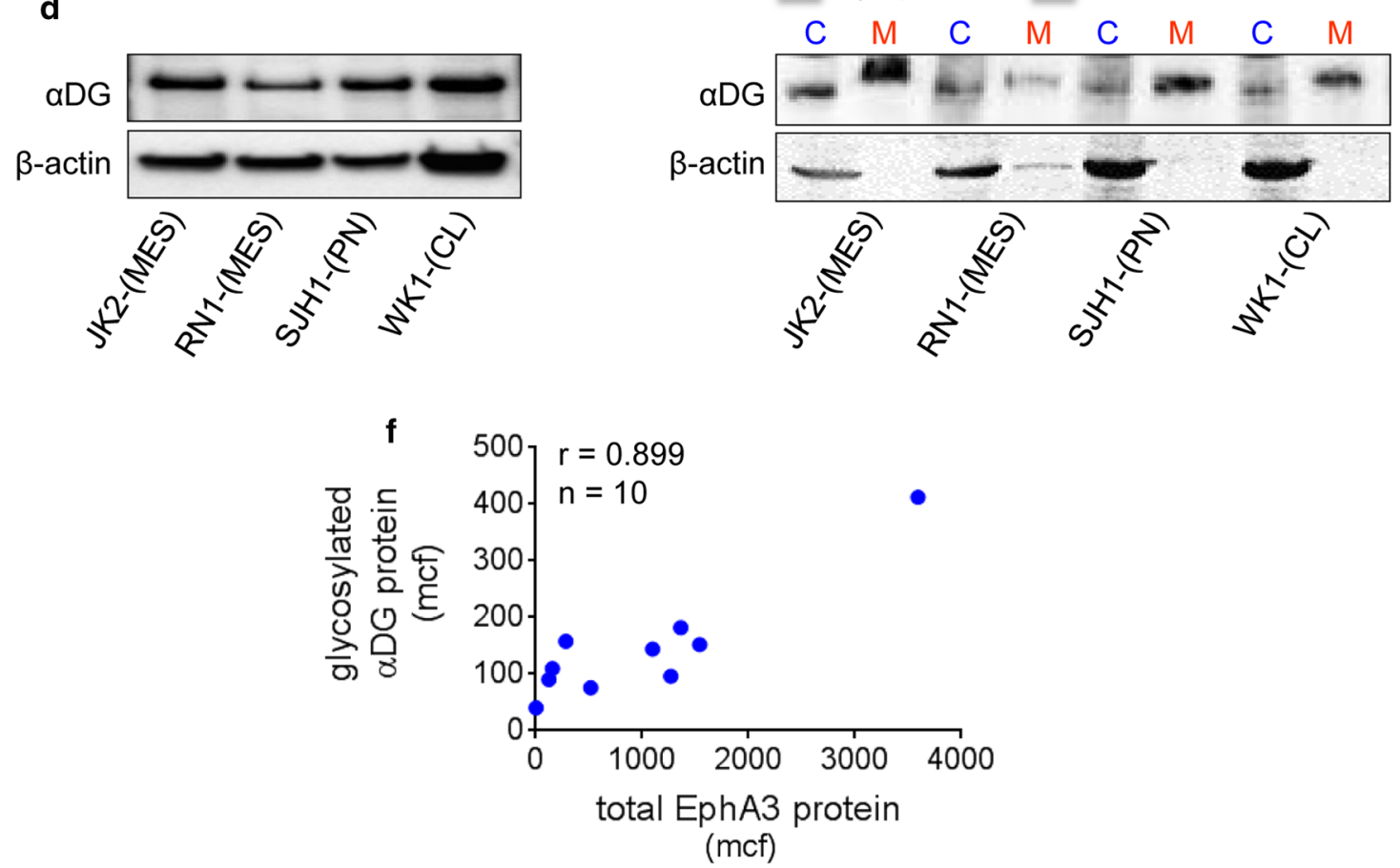
४Fig. 1 Elevated Dystroglycan Correlates with GBM Patient Outcome and $\alpha \mathrm{DG}$ is Abundantly Glycosylated in GBM. a DAG1 expression was correlated with GBM patient survival using the Rembrandt $(n=523)$ and TCGA $(n=453)$ databases. b QPCR analysis of DAG1, ITGA6, EPHA2 and EPHA3 mRNA expression in GBM tissue specimens $(n=28)$. c Flow cytometric analysis for $\alpha D G$ glycosylation (IIH6 mAb) was performed on primary GBM cell lines grown as serum-free GNS cultures, compared to isotype control. See also Online Research 1d for full analysis. d $\alpha$ DG glycosylation was assessed by western blot in four primary GBM cell lines. e $\alpha D G$ glycosylation was assessed by western blot following cell fractionation to compare cytoplasmic versus membrane localisation. $\beta$-actin was used as a loading control. f Flow cytometric analysis was performed for $\alpha \mathrm{DG}$ glycosylation (IIH6 mAb) and EphA3 (IIIA4 mAb) in 10 early passage primary GBM cultures, mean channel fluorescence (mcf) was used to determine the correlation coefficient between EphA3 and glycosylated $\alpha$ DG $(r=0.899)$. GBM subtypes: $M E S$ mesenchymal, $P N$ proneural, $C L$ classical

the figure. Survival plots were generated using Graphpad software. A Log-rank (Mantel-Cox) test was used to determine significance between experimental groups. $P$-values are as indicated, ${ }^{*} p \leq 0.05$ was considered to be statistically significant. In-vitro experiments - a Student's t-test determined the probability of difference; $p<0.05$ was considered significant; all statistical tests were 2 -sided. The correlation coefficient was determined using a Spearman rank.

\section{Results}

\section{Elevated dystroglycan correlates with glioma patient outcome and aDG is abundantly glycosylated in GBM}

$\alpha \mathrm{DG}$ and $\beta \mathrm{DG}$ are transcribed from the Dystrophin-Associated Glycoprotein $1(D A G 1)$ gene. DG is translated as a single pre-pro-polypeptide. The receptor is autocatalytically cleaved into alpha and beta chains that remain noncovalently bound. The mucin-like domain of $\alpha \mathrm{DG}$ becomes heavily glycosylated en-route to the surface membrane. Dystroglycan binds proteins of the extracellular matrix such as laminin by virtue of matriglycan (xylose and glucuronic acid polysaccharide). Receptor glycosylation is essential for proper function, without which $\alpha \mathrm{DG}$ is unable to bind laminin $[19,42]$. To determine if $D A G 1$ was important in the context of brain cancer we interrogated both the Rembrandt and TCGA databases to correlate $D A G 1$ gene expression with survival. In the context of GBM specifically and also glioma, patient tumours with elevated $D A G 1$ led to a significantly shorter survival time (Fig. 1a and Online Resource 1a). The Rembrandt database was also used to assess $D A G 1$ gene expression in GBM as well as other forms of malignant brain cancer versus normal brain tissue. This revealed that $D A G 1$ tended to correlate with tumour grade, as expression was highest in GBM compared to oligodendroglioma and astrocytoma cases, while all tumour types were elevated above normal brain tissue (Online Resource 1b). DAG1 expression in GBM was further stratified into molecular subtype $[8,59,60]$. DAG1 expression was highest in classical (CL) subtype GBM while approximately equivalent in other subtypes, mesenchymal (MES), proneural (PN) (Online Resource 1c). To assess the relative mRNA levels of DAG1 in GBM we performed QPCR on 28 GBM tumour specimens from our in-house tumour bank. We compared expression to other receptors (EPHA2, EPHA3 and ITGA6) previously identified as having a role in GSC maintenance. $D A G 1$ levels were equivalent or higher to these receptors in all cases assessed (Fig. 1b).

Importantly, receptor function correlates closely with glycosylation status rather than gene expression. To determine the level of $\alpha \mathrm{DG}$ glycosylation we used a monoclonal antibody (mAb) (IIH6), previously developed by Campbell and colleagues, specific to glycan moieties on $\alpha \mathrm{DG}$ with known receptor blocking function [20]. We have developed a GBM patient-derived cell line resource (Q-Cell) [14, 57] in which GBM lines are maintained as glioma neural stem cell (GNS) cultures [52]. This approach promotes a more de-differentiated stem cell-like phenotype in culture. We assessed a panel $(n=20)$ of subtype classified $(n=12)$ and unclassified $(n=8)$ early passage GBM cultures generated in-house. Flow cytometric analysis revealed the majority of the lines expressed high levels of glycosylated $\alpha \mathrm{DG}$ irrespective of GBM molecular subtype (Fig. 1c and Online Resource 1d). A panel of four IDH1 WT GBM lines were selected for further analysis, JK2-(MES), RN1-(MES), SJH1-(PN) and WK1-(CL), $\alpha$ DG protein expression was confirmed by western blot (WB) (Fig. 1d). We next performed cell fractionation studies followed by WB on the panel of GBM lines, data indicated the majority of the protein was present in the cell membrane (Fig. 1e).

A previous report in breast cancer had shown that EphA3 could regulate $\alpha \mathrm{DG}$ [63]. Given these findings we assessed the co-expression of glycosylated $\alpha \mathrm{DG}$ and EphA3 protein levels by flow cytometry. Mean channel fluorescence (mcf) analysis revealed a high correlation $(r=0.899)$ between glycosylated $\alpha \mathrm{DG}$ and EphA3 in the primary GBM GNS lines tested $(n=10)$ (Fig. 1f).

\section{Glycosylated aDG is expressed in the vascular niche and discretely on mesenchymal-like glioma tissue}

To examine the spatial localisation and tumour specificity of glycosylated $\alpha \mathrm{DG}$ (hereafter stated as $\alpha \mathrm{DG}$ for simplicity), we first examined a variant of GBM, gliosarcoma (GS), which undergoes a partial process of de-differentiation with secondary loss of the glial differentiation marker GFAP and acquisition of mesenchymal characteristics, a process similar to epithelial-mesenchymal transition (EMT) [45]. GS 

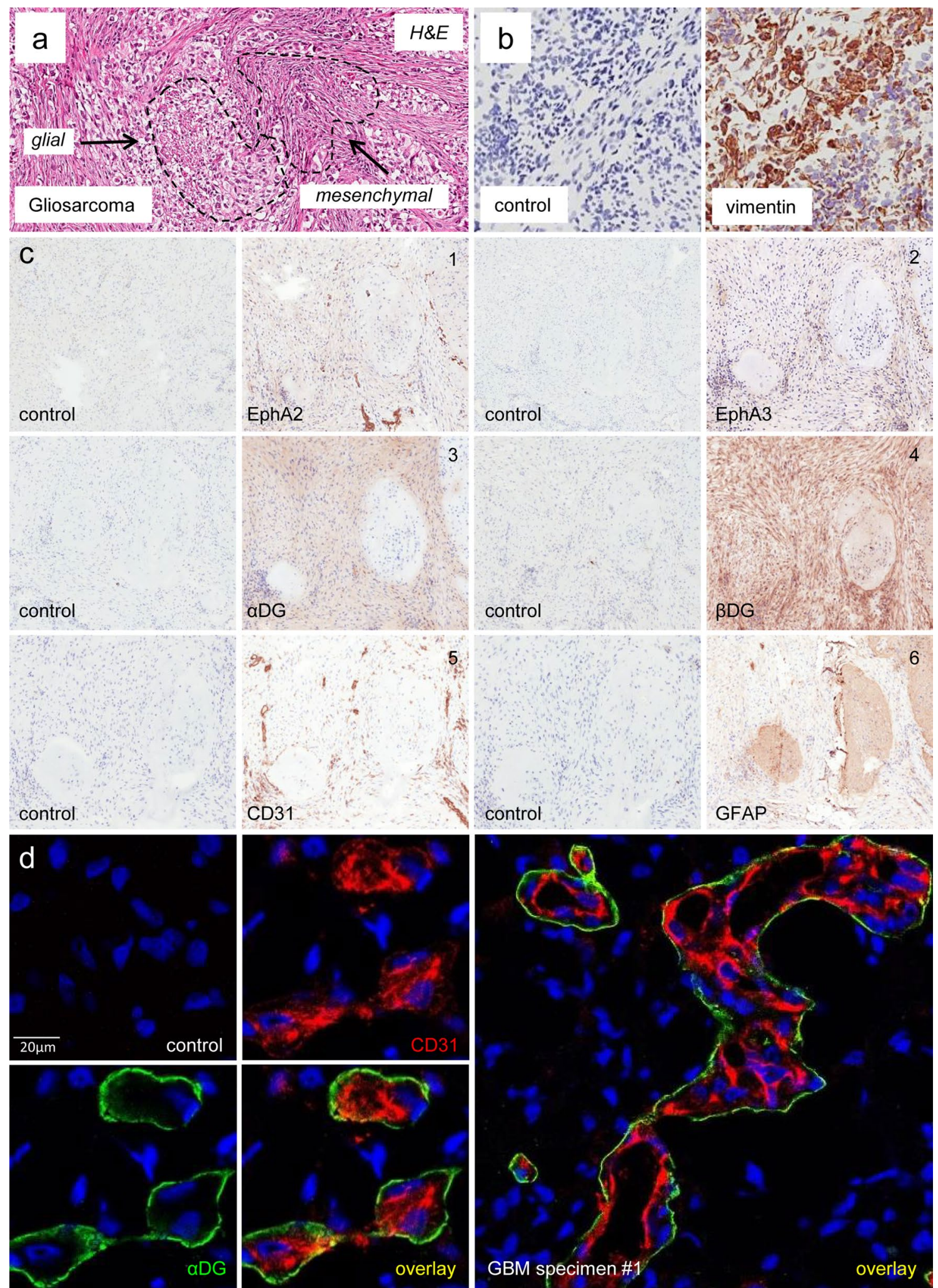

control
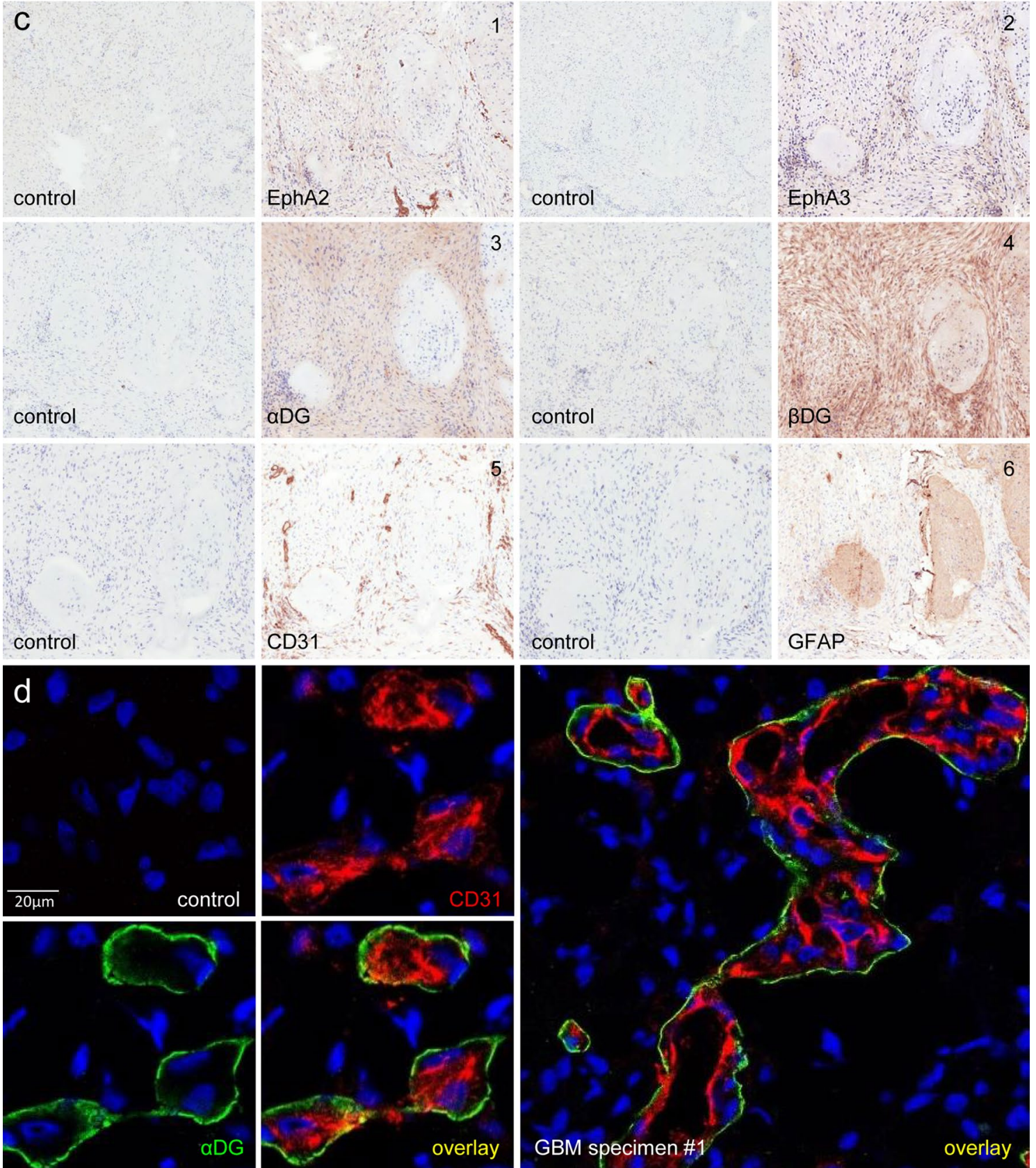

control

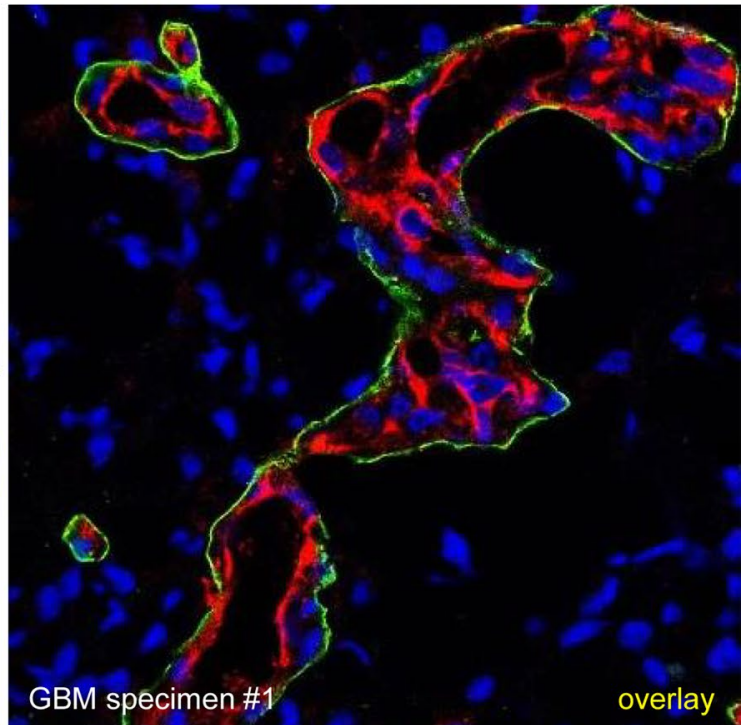

Fig. 2 Glycosylated $\alpha \mathrm{DG}$ is expressed in the vascular niche and discretely on Mesenchymal-like glioma tissue. a H\&E section of a Gliosarcoma (GS) patient specimen showing characteristic biphasic gliomatous (glial-like) and sarcomatous (mesenchymal-like) tumour elements. b IHC analysis of a GS specimen to identify the mesenchymal-like, vimentin ${ }^{+}$, tumour element. c IHC analysis of sequen- tial (\#1-6) GS tissue sections was performed to assess expression patterns of EphA2, EphA3, $\alpha$ DG, $\beta$ DG, CD31 and GFAP. d IF dual staining of a GBM specimen showing localisation of $\alpha \mathrm{DG}$ expression (IIH6-green) surrounding $\left(\mathrm{CD} 31^{+}\right.$—red) tumour blood vessels, nuclei DAPI-blue). See also Online Resource 2 for additional IHC and IF analysis in GBM tissue specimens 
is characterised histologically by a biphasic pattern of gliomatous glial-like $\left(\mathrm{GFAP}^{+}\right)$and sarcomatous mesenchymallike (MES-like) $\left(\right.$ vimentin $^{+}$) tumour elements (morphology shown in Fig. 2a) [27, 45]. Common genetic alterations are found between GBM and GS, and both have a poor prognosis. A known clinical feature of GS is that the mesenchymal tumour compartment is highly migratory and infiltrates ECM protein-rich brain regions such as the leptomeninges [6]. As previously shown by others, the mesenchymal elements stain positive for vimentin [27]. We performed immunohistochemistry (IHC) for vimentin, and found a clear separation between glial-rich and predominantly mesenchymal-rich regions (Fig. 2b). We next performed IHC on sequential GS tumour tissue sections to determine the localisation of $\alpha \mathrm{DG}, \beta \mathrm{DG}, \mathrm{EphA} 2$ and EphA3. A representative example shows that $\alpha \mathrm{DG}$ and EphA3 are expressed predominantly in regions, where mesenchymal tumour elements are present and expression is low or absent on the more differentiated GFAP $^{+}$glial tumour element (Fig. 2c). This discrete pattern was not evident for EphA2 and $\beta$ DG which showed comparable expression in both glial and mesenchymal tumour elements. The observed biphasic tumour tissue pattern in GS also appeared, although less dramatically discrete, in GBM specimens (Online Resource 2a). These regions were smaller and less prominent than in GS tumours, and also showed heterogeneous expression of GFAP, vimentin, EphA2, EphA3 $\alpha$ DG, CD49f and CD31, indicating that this tumour tissue patterning might also occur in GBM (Online Resource 2b). In addition, immunofluorescent (IF) staining revealed in GBM patient specimens $(n=3)$ that $\alpha$ DG staining was strongest in perivascular regions immediately surrounding tumour blood vessels $\left(\mathrm{CD} 31^{+}\right)$(Fig. 2d and Online Resource 2c).

\section{aDG interacts with EphA2 and EphA3 receptors and is expressed on GSCs}

Given the overlapping expression profile of EphA3 and $\alpha \mathrm{DG}$ in GS and GBM tissue we wanted to assess the membrane localisation and potential interaction between these receptors. IF analysis showed a significant overlap in the membrane of EphA2, EphA3 and $\alpha \mathrm{DG}$ in the four primary GBM cell lines tested (Fig. 3a). To assess if these proteins could be complexed together we performed immunoprecipitation (IP) of EphA3 in these lines. Results show co-immunoprecipitation of EphA3 with EphA2 and $\alpha$ DG (Fig. 3b). To further confirm an association between these receptors we performed shRNA mediated EphA3 knockdown (KD) in SJH1 and JK2 cell lines. Following EphA3 KD a commensurate drop in $\alpha \mathrm{DG}$ levels was observed (Online Resource $3 a)$. These data suggest that $\alpha \mathrm{DG}$ and EphA3 are likely associated in the cell membrane.
We next used Amnis image stream technology, a flow cytometric approach which captures single-cell multi-colour fluorescent images. This approach was used to assess cellsurface co-expression of $\alpha \mathrm{DG}$ with known GSC markers. Initially, this was performed on dissociated GBM patient tumour tissue $(n=1)$ obtained directly at time of surgery. Results show strong overlapping expression of $\alpha \mathrm{DG}$ with EphA2, EphA3, CD49f (integrin $\alpha 6$ ), CD133 and CD15 (Fig. 3c). We repeated this analysis using both Amnis and standard flow cytometry using the panel of GBM cell lines $(n=4)$. Results demonstrated a similar pattern of co-expression of $\alpha$ DG especially with EphA2, EphA3 and CD49f, this was less pronounced for CD15, CD29 and CD133 (Fig. 3d and Online Resource 3b,c). To assess stemness characteristics in the $\alpha \mathrm{DG}$ high versus low expressing population we sorted WK1 GBM cells using FACS and performed a neurosphere assay. Results show that neurosphere formation was significantly elevated in the $\alpha \mathrm{DG}^{\text {high }}$ compared to the $\alpha D G^{\text {low }}$ population. In addition, we observed cell changes in the $\alpha \mathrm{DG}^{\text {low }}$ population; low expressing cells that failed to form neurospheres displayed an attached differentiated cell morphology (Fig. 3e). Post $\alpha \mathrm{DG}^{\text {high }}$ versus $\alpha \mathrm{DG}^{\text {low }}$ sort we recombined the two cell populations and assessed $\alpha \mathrm{DG}$ expression overtime. Interestingly, 14 days post-sort both low and high expressing populations were maintained, suggesting that these two unique populations can co-exist in culture for extended periods (Online Resource 3d). $\alpha \mathrm{DG}$ expression and stemness characteristics should be lost following GSC differentiation. To test this we induced differentiation in our neurosphere cultures and $72 \mathrm{~h}$ post-differentiation assessed $\alpha \mathrm{DG}$ expression by flow cytometry and GSC marker expression by QPCR. Results show a marked reduction in $\alpha \mathrm{DG}$ protein expression following differentiation (Fig. 3f), this was accompanied by significant gene downregulation of stemness markers and upregulation of the differentiation markers GFAP, $\beta$ III-tubulin (TUBB3) and OLIG2 (Fig. 3g and Online Resource 3e).

\section{aDG blockade induces GSC differentiation}

To assess the contribution of $\alpha \mathrm{DG}$ glycosylation to the progression of GBM and maintenance of a GSC phenotype, we employed an $\alpha \mathrm{DG}$ mAb (IIH6) which specifically binds and blocks the ability of glycan moieties on $\alpha \mathrm{DG}$ to bind laminin [20]. Following incubation of neurospheres with the IIH6 antibody, we observed a robust and rapid loss of sphere formation compared to cultures incubated with an isotype control $\mathrm{mAb}$ in which sphere integrity was maintained. The response was reliably observed in all primary cultures tested (Fig. 4a). The observed differentiation response was dose dependent, while no response was observed with three independent IgM control antibodies (Online Resource 4a). Neurosphere loss is suggestive of differentiation and loss of 

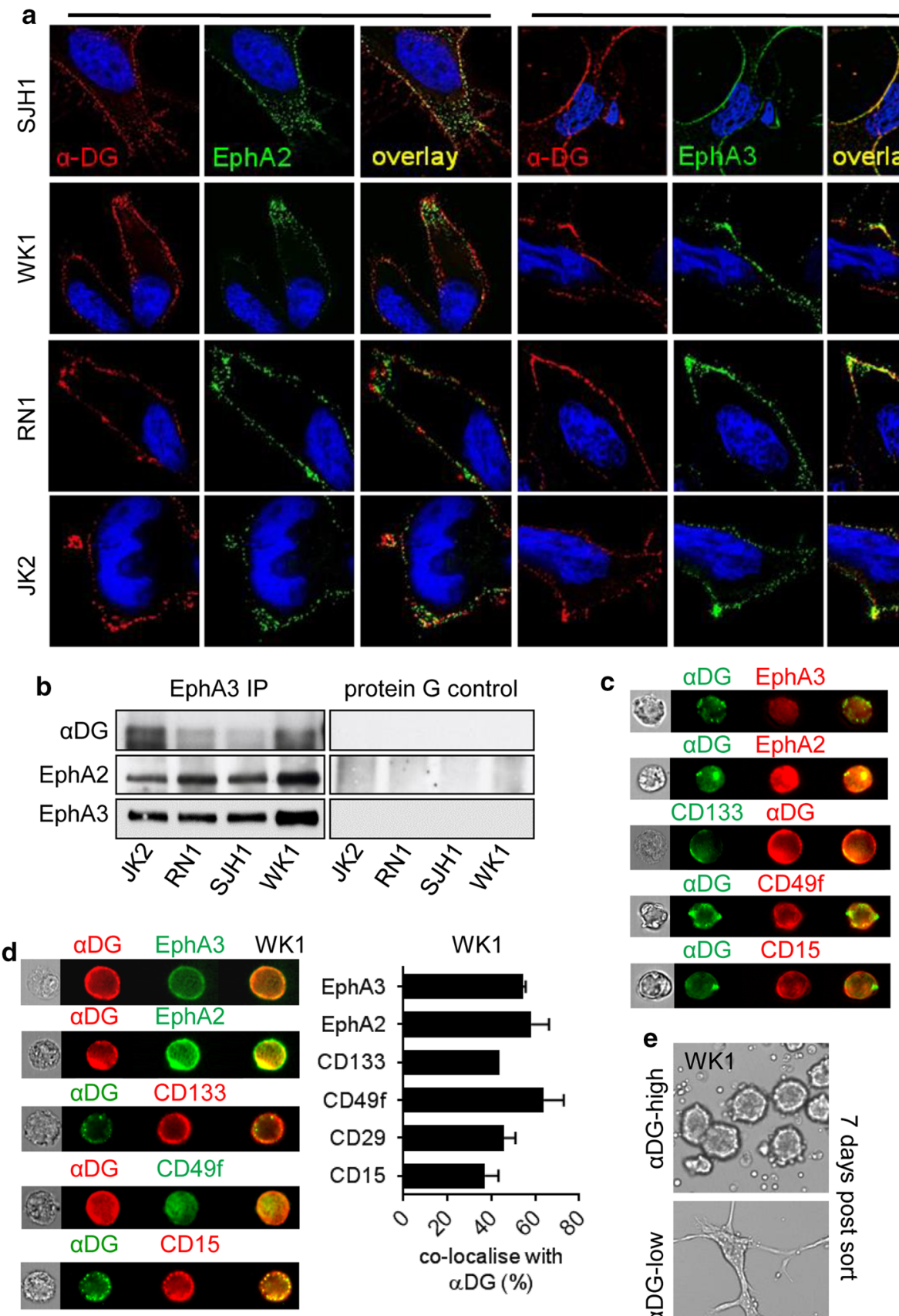

GBM patient tissue
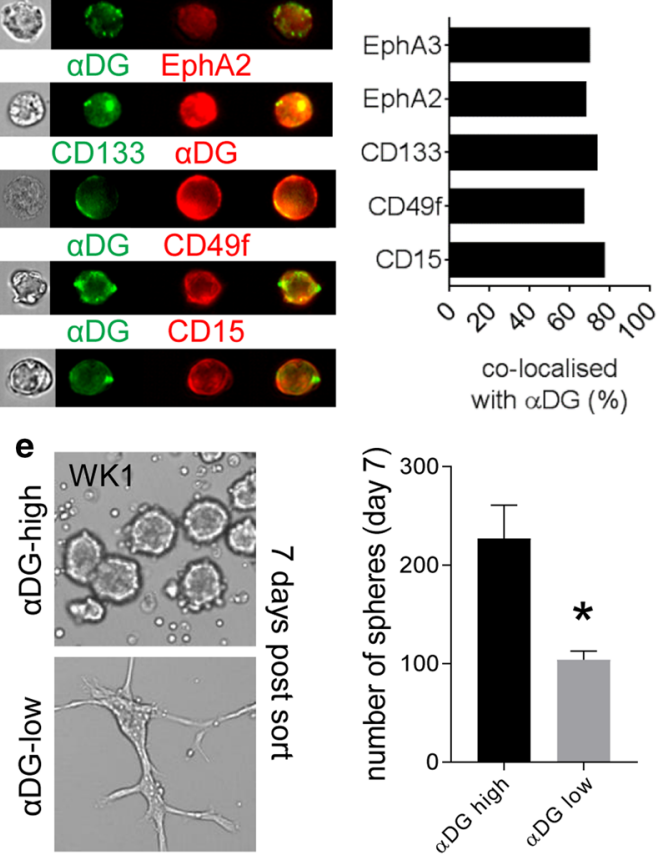

co-localised with $\propto \mathrm{DG}(\%)$
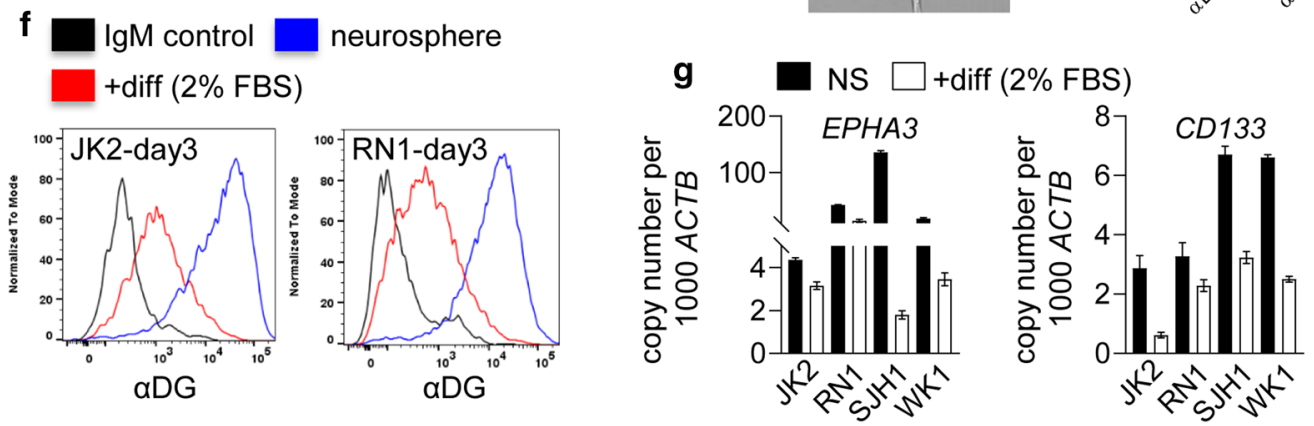
4 Fig. $3 \alpha$ DG Interacts with EphA2 and EphA3 Receptors and is Expressed on GSCs. a IF staining was performed to compare membrane localisation of glycosylated $\alpha \mathrm{DG}$ (IIH6 mAb-red), compared to either EphA2 (1F7 mAb-green) or EphA3 (IIIA4 mAb-green), in four primary GBM cultures. b Immunoprecipitation (IP) for EphA3 was performed from $1 \mathrm{mg}$ of lysate from four early passage primary GBM cultures to compare membrane association of EphA2, EphA3 and glycosylated $\alpha$ DG. Protein G only was used as a control. c Amnis flow cytometric analysis was performed on a dissociated GBM patient tissue specimen $(n=1)$ to assess membrane localisation of glycosylated $\alpha \mathrm{DG}$, with known GSC markers (CD15, CD133, CD49f, EphA2 and EphA3). d Amnis analysis and flow cytometry was performed on primary GBM cultures to assess membrane localisation of glycosylated $\alpha \mathrm{DG}$, with known GSC markers. e $\alpha D G^{\text {high }}$ versus $\alpha D G^{\text {low }}$ populations were isolated from WK1 cells using FACS and cell morphology and sphere number assessed 7 days postsort $\left({ }^{*} p<0.05\right)$. GBM neuropshere differentiation was induced using $2 \%$ FBS, 3 days post-differentiation glycosylated $\alpha \mathrm{DG}$ expression was assessed by flow cytometry and GSC and diff marker expression assessed by QPCR and compared to undifferentiated cells, see Online Resource 3 for complete analysis. All data presented as the mean \pm SD of three independent experiments

proliferative ability. Differentiation was confirmed by acquisition of neuronal ( $\beta$ III-tubulin) and glial (GFAP) lineage markers (Fig. 4b and Online Resource 4b). This differentiation response was quantitated using IncuCyte technology in real time and showed pronounced cell-attachment following IIH6 treatment (Fig. 4c). The observed differentiation response was accompanied with a significant reduction in proliferation $(p<0.01)$ (Fig. $4 \mathrm{~d})$. We observed negligible cell death induction in the short term $(48 \mathrm{~h})$ following antibody treatment (Fig. 4e and Online Resource 4c). Interestingly, the differentiation effects were reversible if antibody was removed within seven days of treatment. If additional IIH6 mAb was added at seven days, the majority of rechallenged tumour cells showed pronounced cell morphology changes and ultimately underwent cell death within two weeks (Fig. 4f). These data highlight the ability of GBM cells to recover during early differentiation but also susceptibility to prolonged terminal differentiation induced by the IIH6 antibody.

\section{aDG controls ERK signalling to regulate GSCs and promote an MES-like GBM state}

Sustained ERK activation, as distinct from transient signalling, induces translocation of ERKs to the nucleus resulting in pro-differentiation transcriptional changes in neuronal cells [38]. Based upon our previous work and also the studies of others, it appears this mechanism is also observed in a number of cancers including GBM $[13,16]$. We, therefore, assessed ERK activation following IIH6 treatment and found that pERK activation was sustained $24 \mathrm{~h}$ post-treatment (Fig. 5a). Analysis of pERK cellular localisation, following IIH6 treatment, showed that activated ERK was predominantly localised the nucleus. The observed response was equivalent to a positive differentiation control ( $2 \%$ FBS), while in control-treated cells, the majority of pERK was retained in the cytoplasm (Fig. 5b). To examine if this same mechanism was operative in patient tissue and not an artefact of culture we assessed sequential (\#1-4) GS tumour sections by IHC for $\alpha$ DG, EphA3, GFAP, pERK and Ki67. Results confirmed co-expression of $\alpha \mathrm{DG}$ and EphA3 in the mesenchymal fraction which was discrete from the more differentiated $\mathrm{GFAP}^{+}$glial fraction. pERK IHC staining revealed clear co-expression with the $\mathrm{GFAP}^{+}$glial-predominant tumour regions which also showed less proliferation as shown by very low level Ki67 staining (Fig. 5c). This data confirmed that sustained ERK activation occurs in high-grade glioma tissue and is restricted to the more differentiated, GFAP ${ }^{+}$, less mitotically active tumour regions.

A study in breast cancer found that tumour cell populations differ in expression of integrin $\alpha 6$ cytoplasmic domain splice variants; $\alpha 6 \mathrm{~A}$ is expressed on epithelial tumour cells while $\alpha 6 \mathrm{~B}$ on mesenchymal tumour cells [26]. Data show that $\alpha 6 \mathrm{~B}$ is the critical variant driving EMT and cancer stem cell function and promotes tumour initiation. Laminin-integrin interactions can activate ERK but only in cells expressing predominantly $\alpha 6 \mathrm{~A}$ with an intact cytoplasmic tail, not $\alpha 6 \mathrm{~B}$ [61]. While DG when bound to laminin, can suppress integrin a6-mediated ERK activation [23]. Integrin $\alpha 6$ has previously been demonstrated to be expressed and functional in the GSC niche and is typically active in the process of niche formation and basement membrane attachment [11, 34]. We assessed $\alpha 6 \mathrm{~A}$ and $\alpha 6 \mathrm{~B}$ mRNA expression via QPCR in $28 \mathrm{GBM}$ specimens. Results show that $\alpha 6 \mathrm{~B}$ and the mesenchymal markers $\mathrm{N}$-cadherin and Slug are predominantly expressed, while $\alpha 6 \mathrm{~A}$ and the epithelial marker E-cadherin are essentially absent (Fig. 5d). We also investigated the relative mRNA levels of $\alpha 6 \mathrm{~A}$ and $\alpha 6 \mathrm{~B}$ in 6 primary GBM GNS cell lines and found an average 12.1 fold increase in $\alpha 6 \mathrm{~B}$ compared to $\alpha 6 \mathrm{~A}$. This correlated with an average 210 fold increase in the mesenchymal marker $\mathrm{N}$-cadherin compared to the E-cadherin (Online Resource 5a). In addition, $\alpha 6 \mathrm{~B}$ correlated highly with mesenchymal and GSC markers in the primary GNS lines tested $(n=6)$ (Fig. 5e). The oncogene BMI-1 is a stem cell factor and polycomb group family member that functions as a repressor of the splicing factor ESRP-1. Mercurio and colleagues show, in breast cancer, that $\alpha 6 \mathrm{~B}$ is positively controlled by autocrine VEGF-A signalling that culminates in transcriptional repression of the RNA-splicing factor ESRP-1 [26]. We, therefore, assessed BMI-1, VEGF-A and ESRP-1 mRNA levels by QPCR in GNS cell lines $(n=6)$ (data not shown) and GBM tissue $(n=28)$, this revealed high levels of BMI-1 and VEGF-A, while ESRP-1 levels were undetected (Fig. 5f). This suggests that a similar mechanism to that observed in breast cancer could be operative in GBM. To determine if integrin $\alpha 6$ was responsible for driving sustained ERK activation following 


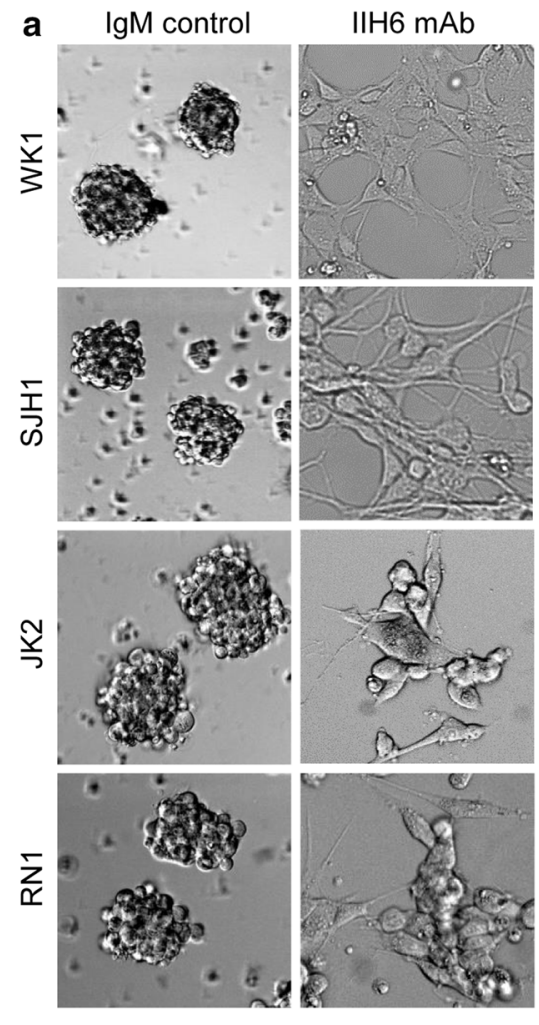

c $\square$ aDG blocking $\mathrm{mAb}(\mathrm{IIH} 6)$
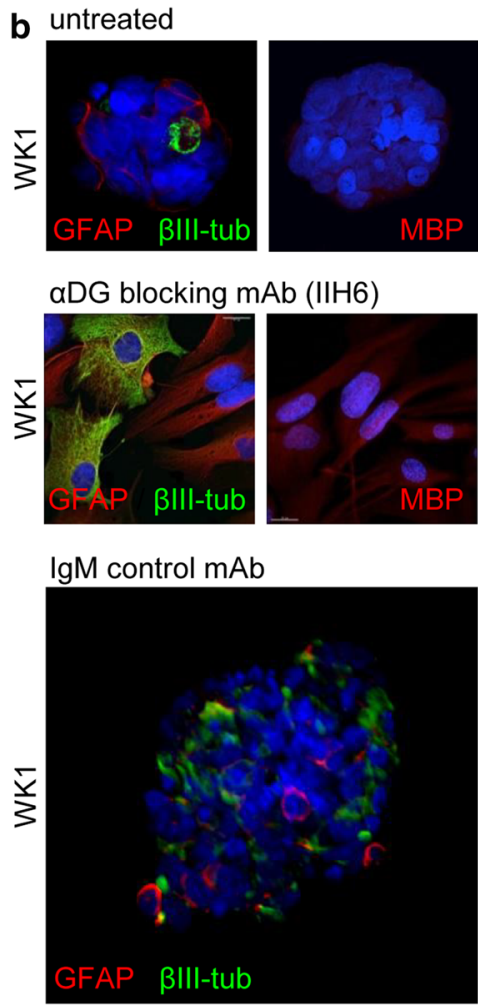

IgM control $\lg \mathrm{M}$ control $\mathrm{mAb}$

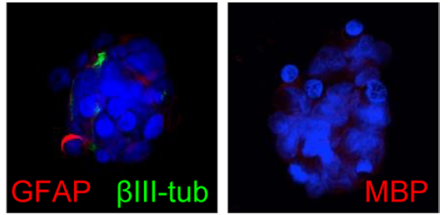

isotype control

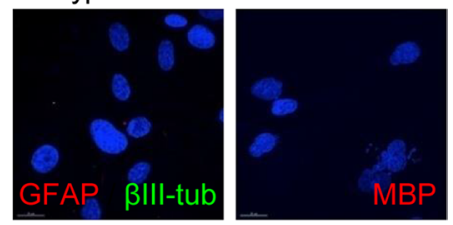

aDG blocking mAb (IIH6)
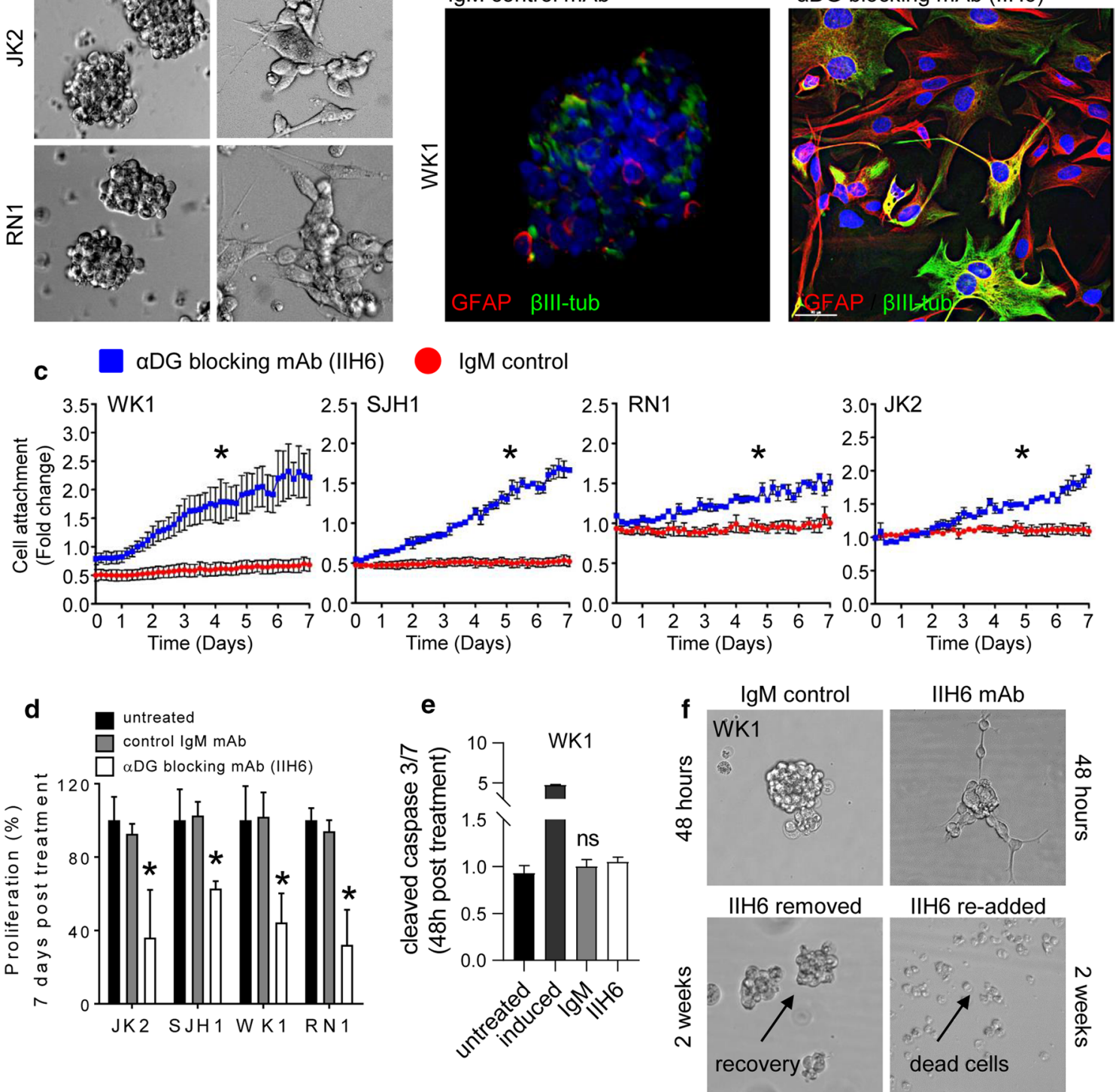

IIH6 treatment we performed an integrin $\alpha 6$ shRNA mediated KD compared to control shRNA. These cells were then treated with the IIH6 blocking mAb, KD of integrin $\alpha 6$ did not reverse the differentiation response. A similar response was observed when cells were pre-treated with the integrin $\alpha 6$ blocking mAb GoH3 (Online Resource 5b, c). The GoH3 blocking antibody had little effect when used as a single agent on multiple GNS cell lines and did not appear 
४Fig. $4 \alpha$ DG Blockade Induces GSC Differentiation. a Four primary GBM neurosphere cultures treated with the $\alpha \mathrm{DG}$ blocking mAb (IIH6, $50 \mu \mathrm{g} / \mathrm{ml}$ ) and an equivalent IgM control $(50 \mu \mathrm{g} / \mathrm{ml})$. Bright field images $24 \mathrm{~h}$ post-treatment showing loss of neurosphere formation and cell adherence. b IF staining was performed $48 \mathrm{~h}$ post IIH6 mAb treatment for the differentiation markers (GFAP-red, $\beta$ IIItubulin — green, myelin basic protein (MBP)—red and the nuclear counter-stain DAPI-blue). WK1 data shown see also Online Resource $4 \mathrm{~b}$ for complete analysis. $\mathbf{c}$ IncuCyte analysis was performed to quantitate cell adhesion in real time following IIH6 treatment-blue compared to an equivalent IgM control-red for 7 days $\left({ }^{*} p<0.05\right)$. d Cell proliferation was assessed by direct cell counting using a haemocytometer 7 days post IIH6 treatment compared to IgM control and untreated cells $(* p<0.01)$. e ApoTox-Glo Triplex assay was used to assess caspase $3 / 7$ activity and cell viability $48 \mathrm{~h}$ post IIH6 treatment. WK1 data shown see also Online Resource 4c for complete analysis. f Neurosphere formation was assessed in WK1 cells following IIH6 withdrawal or re-addition following 7 days initial treatment. Bright field images at 2 weeks showing neurosphere re-formation following IIH6 withdrawal and cell death following IIH6 rechallenge. Data presented as the mean \pm SEM of three independent experiments

to induce a differentiation response (data not shown). GoH3 treatment alone appeared to induce very low level ERK activation (Fig. $5 \mathrm{~g}$ ). This was expected given the majority of integrin $\alpha 6$ present is the $\alpha 6 \mathrm{~B}$ splice variant with a truncated intracellular tail with reduced ERK signalling capacity. When IIH6 was combined with GoH3 we observed a somewhat more rapid differentiation response, this coincided with an increased level of sustained ERK activation than IIH6 alone $24 \mathrm{~h}$ post-treatment (Fig. $5 \mathrm{~g}$ ), and a greater reduction in cell proliferation (Fig. 5h). Indicating that the sustained ERK activation, observed following IIH6 treatment, was not driven through integrin $\alpha 6$.

As described above, EphA3 is co-localised with dystroglycan and integrin $\alpha 6$. Following EphA3 IP we observed co-immunoprecipitation of EGFR in GBM cells, suggesting that EGFR is also present as a part of this complex and may be involved in regulating ERK activation (Online Resource 5d). To test if EGFR was responsible for driving sustained ERK activation following antibody treatment, neurospheres were pre-treated with either Gefitinib $(2 \mu \mathrm{M})$ or Erlotinib $(2 \mu \mathrm{M})$ prior to IIH6 treatment. EGFR inhibition did not prevent the induction of differentiation (Online Resource 5e). Taken together, this data suggests that $\alpha \mathrm{DG}$ when bound to laminin, forms a complex with EphA2, EphA3, integrin $\alpha 6 \mathrm{~B}$, EGFR and likely other receptors to mediate a de-differentiated GSC mesenchymal-like phenotype through tight regulation of ERK signalling.

\section{DAG1 down-regulation delays or prevents GBM formation in-vivo}

To further define DG function in GBM we performed lentiviral DAG1 shRNA mediated KD, using a combination of five target-specific 19-25 nucleotide sequences against
$D A G 1$, four GBM neurospheres lines were tested. Following effective constitutive KD in JK2, RN1 and WK1 cells (Fig. 6a), we observed a significant $(p<0.05)$ reduction in proliferation (Fig. 6b) and neurosphere loss typical of differentiating GBM cells (Fig. 6c). In the case of SJH1, we observed a florid response to $D A G 1 \mathrm{KD}$; all cells underwent cell death within 7-14 days following KD (Online Resource 6a). Given this rapid response, SJH1 cells were excluded from further analysis. In-vitro DAG1 KD also reduced expression of EphA2, EphA3 and CD49f (integrin $\alpha 6$ ) while markedly increasing the expression of the glial differentiation marker GFAP, indicating KD was inducing glial lineage differentiation (data shown for JK2) (Online Resource 6b). To explore if $D A G 1 \mathrm{KD}$ reduced the tumourigenic potential of GBM cells in-vivo we performed orthotopic engraftment of control shRNA versus DAGl KD cells into the right striatum of NOD/SCID mice. Animals were euthanised when signs of illness or disease burden were observed. The two highest DAG1 expressing lines (WK1-(CL), JK2-(MES)) were selected. Kaplan Meier survival analysis for WK1 showed DAG1 KD significantly increased overall survival $p=0.0266(n=4)$, median survival for control was 94 days versus DAGl KD 109 days (Fig. 6d). qPCR analysis of postmortem tumour tissue confirmed a significant $(p<0.01)$ reduction in DAG1 mRNA levels compared to control shRNA engrafted animals (Online Resource 6c). Positive tumour formation was confirmed by haematoxylin and eosin (H\&E) staining in all control and DAG1 KD engrafted animals (Online Resource 6d). Kaplan Meier survival analysis for JK2 showed DAG1 KD significantly increased overall survival $p=0.0043(n=7)$, with no animals reaching survival endpoint, whereas median survival for control group was 195 days (Fig. 6d). All DAG1 KD animals developed spontaneous thymic lymphoma, which is a common occurrence in this strain, and were euthanised as per our ethical guidelines [53]. Positive tumour formation was confirmed by $H \& E$ staining in all control shRNA engrafted animals, while no clinical signs of intracranial tumour formation were observed in DAGl KD animals or intracranial tumour detected by H\&E staining post-mortem (Fig. 6e).

\section{Discussion}

While decades of research have greatly increased our understanding of GBM, this knowledge is yet to translate into meaningful survival benefit for patients. We are now only starting to fully appreciate the true complexity and functional cellular states that reside within these aggressive tumours [46]. This plasticity and complex interaction with the TME is largely responsible for the modest clinical progress achieved to-date. Solid tumours, such as GBM, also harbour populations of cancer cells with stem cell-like 

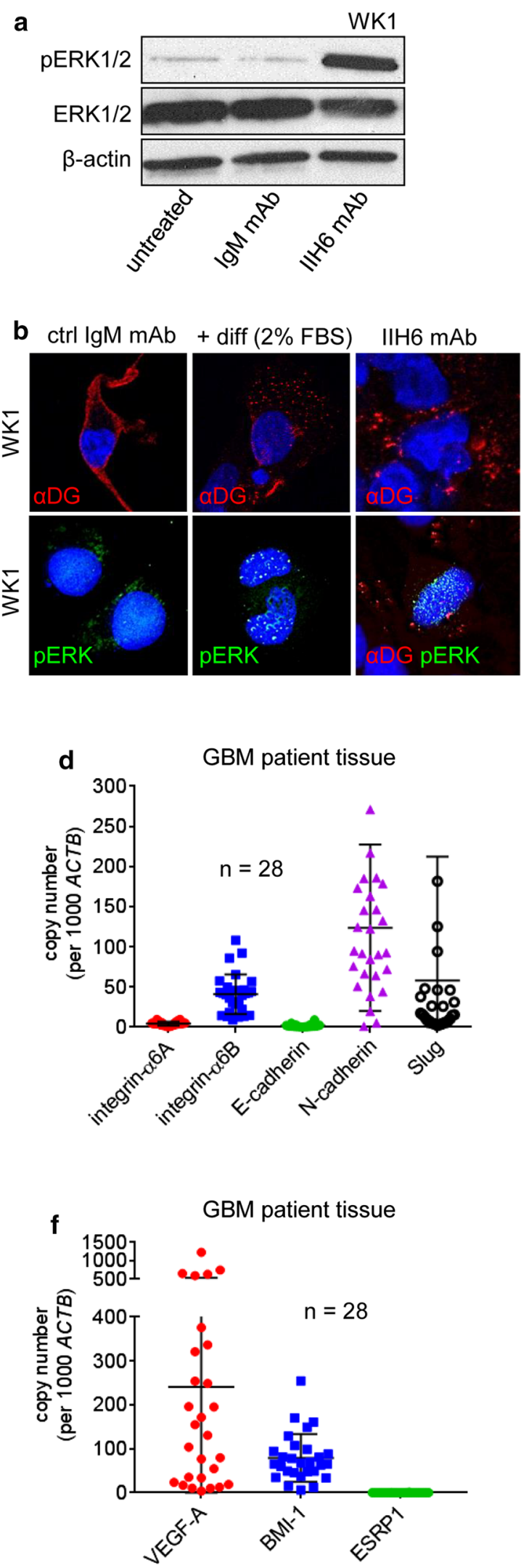

c sarcomatous (MES-like) gliomatous (glial-like)

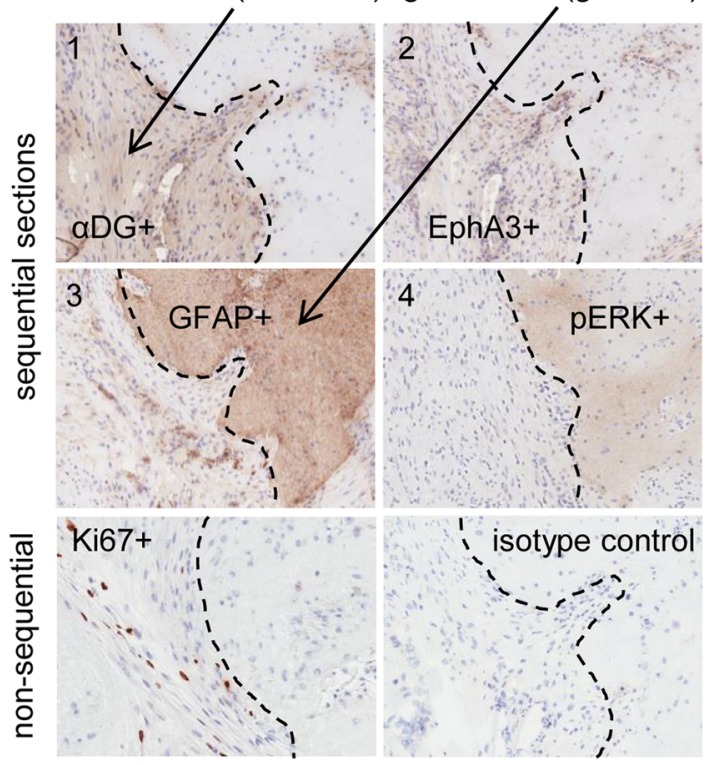

\begin{tabular}{|l|l|l|l|}
\hline e Correlation co-efficient ( $r$ ) with integrin $\alpha 6 \mathrm{~B}$ \\
\hline Mesenchymal Markers & GSC Markers \\
\hline Slug & 0.9022 & EphA3 & 0.9650 \\
\hline Snail & 0.1053 & CD15 & 0.9370 \\
\hline Twist & 0.8521 & CD133 & 0.0235 \\
\hline Vimentin & 0.5916 & CD49f & 0.9962 \\
\hline N-cadherin & 0.5043 & SOX2 & 0.9948 \\
\hline mRNA data from 6 GBM cell lines & \\
\hline
\end{tabular}
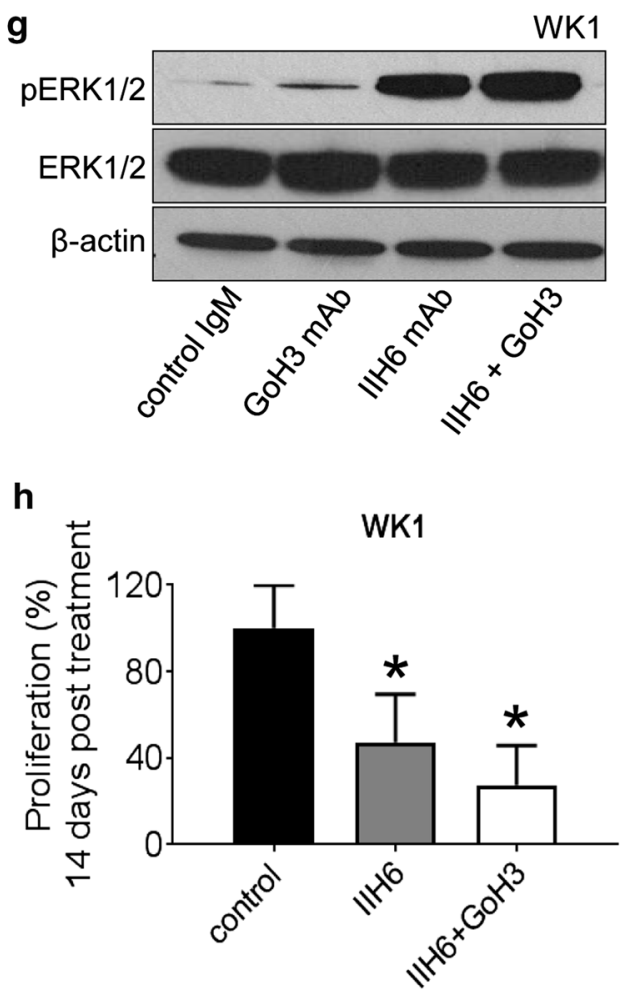
4Fig. $5 \alpha$ DG Controls ERK Signalling to Regulate GSCs and Promote an MES-like GBM State. a ERK1/2 phosphorylation (pERK1/2) was assessed by western blot in WK1 GBM neurospheres following IIH6 $(50 \mu \mathrm{g} / \mathrm{ml})$ treatment for $24 \mathrm{~h}$, compared an equivalent IgM control $\mathrm{mAb}(50 \mu \mathrm{g} / \mathrm{ml})$ and untreated cells. $\beta$-Actin was used as a loading control. b IF staining was performed $24 \mathrm{~h}$ post IIH6 mAb treatment for pERK1/2 - green and $\alpha \mathrm{DG}$ - red to assess nuclear versus cytoplasmic localisation, 2\% FBS was used as positive differentiation control. c IHC analysis of sequential (\#1-4) GS tissue sections was performed to assess discrete expression patterns of $\alpha \mathrm{DG}$, EphA3, GFAP, pERK and Ki67 (non-sequential). d QPCR analysis of integrin $\alpha 6 \mathrm{~A}$, integrin $\alpha 6 \mathrm{~B}$, E-cadherin, $\mathrm{N}$-cadherin and Slug mRNA expression in GBM specimens $(n=28)$. e Correlation coefficient analysis of mRNA expression of the mesenchymal markers (Slug, Snail, Twist, Vimentin and N-cadherin) and the GSC markers (EphA3, CD15, CD133, CD49f and SOX2) in 6 primary early passage GBM GNS cultures. f QPCR analysis of VEGF-A, BMI-1 and ESRP1 mRNA expression in GBM specimens $(n=28)$. g ERK1/2 phosphorylation (pERK1/2) was assessed by western blot in WK1 GBM neurospheres following GoH3 $(10 \mu \mathrm{g} / \mathrm{ml})$ or IIH6 $(50 \mu \mathrm{g} / \mathrm{ml})$ either alone or in combination compared an equivalent control mAb combination $\operatorname{IgG} 2 \mathrm{a}(10 \mu \mathrm{g} / \mathrm{ml}) / \mathrm{IgM}(50 \mu \mathrm{g} / \mathrm{ml}), \beta$-actin was used as a loading control. h Cell proliferation was assessed by direct cell counts using a haemocytometer 7 days post IIH6 treatment alone or combined with $\mathrm{GoH} 3$. Data presented as the mean $\pm \mathrm{SD}$ of three independent experiments, ${ }^{*} p<0.05$

abilities. These GSCs have the potential for self-renewal, tumour initiation and recurrence and often reside in necrotic and perivascular regions [28]. A better understanding of GSC biology and the functional elements that drive these dynamic cellular states in GBM will be required before meaningful clinical advances are likely to be made.

Dystroglycan biology and function in the brain is relatively understudied and less is known in the context of GBM. Concordant with our findings, Petrucci and colleagues found that transmembrane $\beta \mathrm{DG}$ was highly expressed on the majority of brain tumour tissue. They reported reduced $\alpha \mathrm{DG}$ expression in two serum grown immortalised GBM cell lines (U87-MG and A172-MG) and showed positive expression in one EphA3 ${ }^{+}$GBM cell line (U251-MG), which we subsequently confirmed [10]. By flow cytometric analysis, we found significant $\alpha \mathrm{DG}$ expression in 17/20 early passage primary GBM samples grown as serumfree GNS cultures. There appeared to be no correlation of expression with molecular subtype, this was expected as GNS cultures were grown on a basement membrane of laminin or matrigel which tends to promote a more MESlike de-differentiated phenotype irrespective of molecular subtype [5, 59, 62]. Our IHC and IF expression analysis demonstrated strong $\alpha \mathrm{DG}$ expression around brain tumour blood vessels in patient specimens. This perivascular expression pattern confirms those of an earlier study [49]. We also detected abundant $\alpha \mathrm{DG}$ expression in vimentin ${ }^{+}, \mathrm{EphA} 3^{+}$, GFAP $^{\text {low }}$ MES-like tumour regions. The number of Ki67 positive cells was elevated in $\alpha \mathrm{DG}^{+} / \mathrm{EphA} 3^{+} /$vimentin $^{+}$ tumour regions compared to other regions, suggesting this tumour compartment was more mitotically active. Furthermore, we noted distinct morphological differences, $\alpha \mathrm{DG}^{+}$/ EphA $3^{+} /$vimentin $^{+}$regions had an elongated, mesenchymal morphology, while negative regions had a more rounded, immotile appearance. While evident in both GBM and the GS tumours, this observation was most marked in GS and is consistent with disease biology, where the vimentin ${ }^{+}$ MES-like (sarcomatous) tumour cells are highly motile and migrate to BM-rich regions in the brain such as the leptomeninges [36, 37, 45]. GS is an uncommon variant of GBM and, despite exhibiting distinct sarcomatous and gliomatous tumour morphologies, are monoclonal tumours with GBMassociated genetic alterations [6]. While GBM are not epithelial tumours, the mesenchymal differentiation observed in GS tumours has been reported to occur through an EMT-like process [45]. In GBM we observed a similar, less prominent, pattern of MES-like $\alpha \mathrm{DG}^{+} /$vimentin $^{+}$tumour tissue often detected in large tumour sections, indicating that GBM may also undergo a similar EMT-like process. Recently seminal studies from Suva and colleagues have described four states that exist within single GBM tumours to varying degrees. These states (MES-like, NPC-like, OPC-like and AC-like) are all driven by unique elements within the tumour and display unique properties [46]. They show that the MESlike NF1-driven regions express vimentin highly and interact frequently with the TME and immune infiltrate. Similar to our findings, they show that MES-like tissue contained considerable subsets of proliferating cells, reflecting the aggressive nature of the MES-like tumour compartment. Taken together, our data suggests that $\alpha \mathrm{DG}$, along with EphA3, are critical components of this MES-like tumour state, promoting functional interaction with BM proteins likely within the TME and perivascular niche.

We also observed a strong co-expression of $\alpha \mathrm{DG}$ with other known GSC markers. This is not surprising given the recently identified roles of DG in regulating neural stem and progenitor cell commitment in the postnatal SVZ [39]. We found disruption of the strong connection of DG to laminin, either by $\alpha \mathrm{DG} \mathrm{mAb}$ blockade or $D A G 1$ downregulation, led to pronounced loss of stem cell-like characteristics and induction of differentiation. Interestingly, the in-vitro effects of $\alpha \mathrm{DG}$ mAb blockade were reversible within one week of treatment, while prolonged treatment resulted in tumour cell death suggestive of irreversible, terminal differentiation. Invivo DAG1 KD studies were conducted using two models, WK1 (CL) and JK2 (MES), in the later mesenchymal model no tumours were detected in all DAG1 KD animals including a single animal which survived for 598 days post engraftment. Suggesting a strong reliance on $\alpha \mathrm{DG}$ to tumour progression in this mesenchymal subtype model.

The strong link we found between $\alpha \mathrm{DG}$ and EphA3 further confirmed our previous findings connecting EphA3 to an MES-like GSC phenotype [13]. A recent 

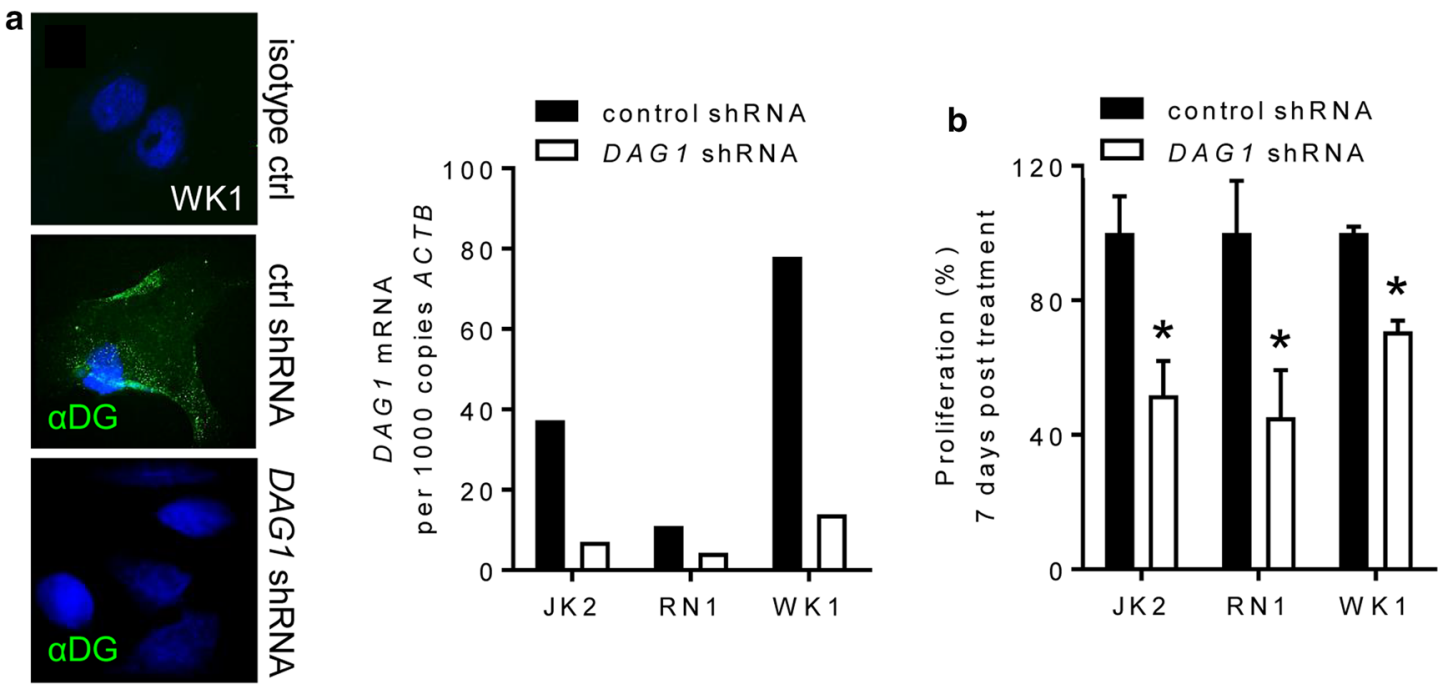

c control shRNA
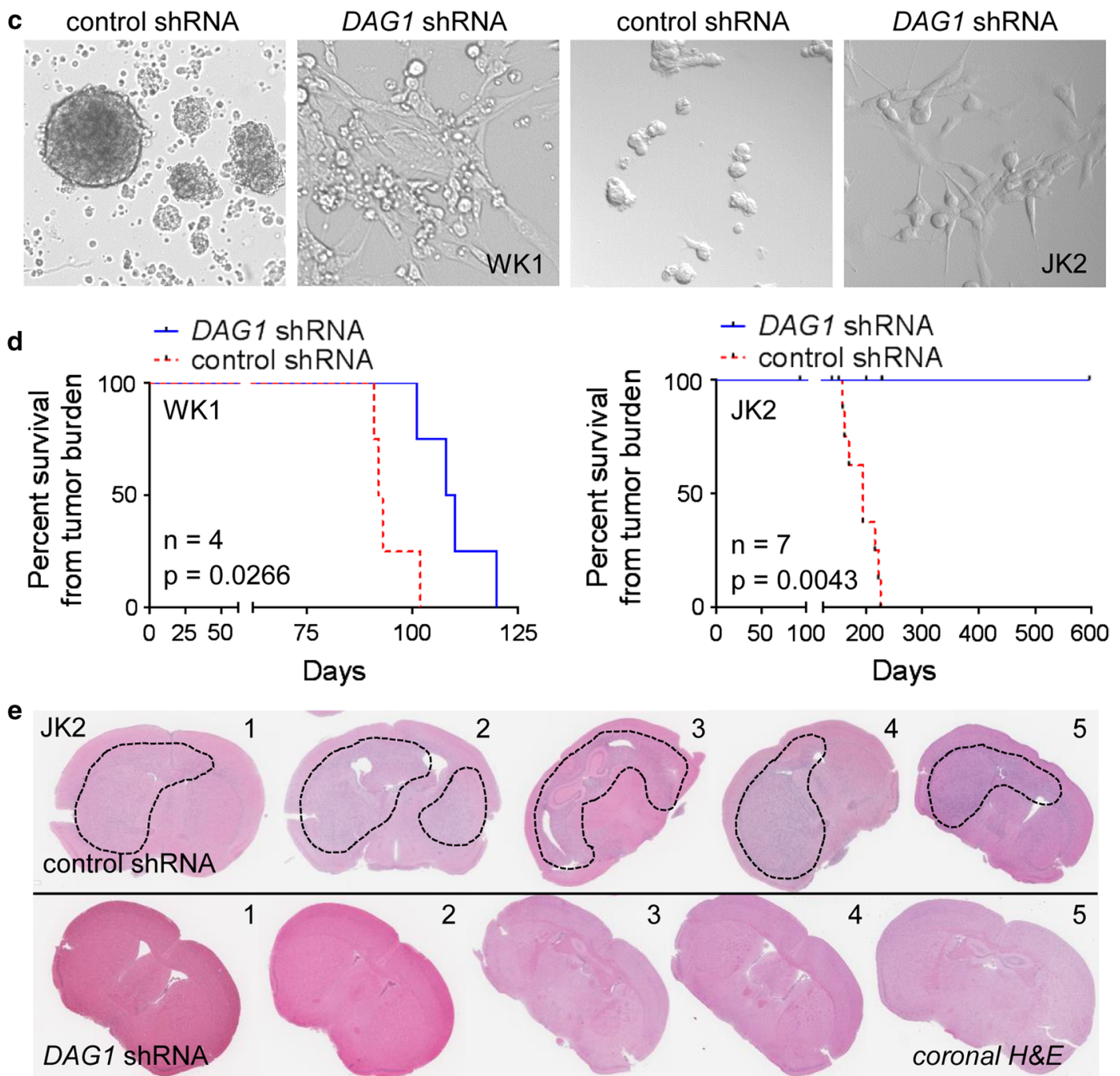

report by Singh and colleagues have shown that EphA3 is significantly elevated in recurrent GBM and cooperates with EphA2 to promote tumourigenesis [54]. Based on these findings, $\alpha$ DG may also be enriched in recurrent GBM. Sustained ERK activation induces translocation of ERKs to the nucleus resulting in pro-differentiation 
4Fig. 6 DAG1 down regulation delays or prevents GBM formation in-vivo. a IF staining and QPCR was used to assess DAG1 mRNA levels following shRNA mediated KD in primary GBM cell lines. b Cell proliferation was assessed by direct cell counts using a haemocytometer following stable DAG1 KD. Data presented as the mean $\pm \mathrm{SD}$ of three independent experiments, ${ }^{*} p<0.05$. c Bright field images of WK1 and JK2 neurospheres 2 week post-DAG1 shRNA KD compared to control shRNA transfected cells. See also Online Resource 6a for SJH1 images. d Kaplan Meier analysis showing a significant $p<0.05$ increase in overall survival following orthotopic intracranial engraftment of $1 \times 10^{5}$ DAG1 shRNA versus control shRNA cells into the right striatum of NOD-SCID mice. WK1 $n=4$ animals per arm, JK2 $n=7$ animals per arm. e Representative H\&E coronal sections from DAG1 shRNA versus control shRNA engrafted animal following euthanasia from either illness or tumour burden. See Online Resource 6d for WK1 H\&E images

transcriptional changes in normal neuronal cells and some forms of cancer [16, 38]. In our previous work, we found EphA3 KD in GBM induced sustained ERK activation which induced differentiation and reduced cell growth and tumourigenicity [13]. This appeared true for $\alpha \mathrm{DG}$, antibody-mediated receptor blockade also led to sustained ERK activation and translocation of ERKs to the nucleus followed by GSC differentiation and ultimately cell death. We also observed this phenomenon in patient tissue, where more differentiated, $\mathrm{GFAP}^{+} \mathrm{Ki}^{\mathrm{low}}{ }^{\text {low }}$ vimentin ${ }^{\text {low }}$, tumour regions stained positive for phosphorylated ERK1/2, highlighting an active process during disease progression.

While the integrin- $\alpha 6 \mathrm{~A}$ splice variant, through interaction with laminin, can activate the ERK pathway, our mRNA expression analysis of 28 tumour specimens showed that the integrin- $\alpha 6 \mathrm{~B}$ splice variant was predominantly expressed in GBM and correlated with mesenchymal markers. $\alpha 6 \mathrm{~B}$ is strongly linked with a mesenchymal stem cell signature in breast cancer [26], and has a truncated intracellular domain which cannot actively signal the ERK pathway [61]. Thus, in GBM when $\alpha \mathrm{DG}$ is bound to BM proteins such as laminin, $\beta D G$ most likely sequesters MEK and ERK to prevent ERK pathway activation, $[23,56]$ (see model Fig. 7). Our findings indicate that the $\alpha$-subunit of the DG receptor, when bound to laminin, is predominantly acting as a brake on ERK activation, thereby maintaining GSCs and the MESlike population within BM-rich regions and niches within these tumours.

DG is expressed widely throughout the body, especially in skeletal muscle, making potential therapeutic targeting of this receptor challenging. It appears that unique brain dystroglycan glycoepitopes have been identified and antibodies raised to recognise these unique glycan moieties [40]. It is conceivable that an $\alpha \mathrm{DG}$ brain-specific targeting antibody could be developed, though targeting of normal brain would still be undesirable. This could be overcome through the use of bi-specific targeting strategies with tumour-specific antigens, such as EphA3.

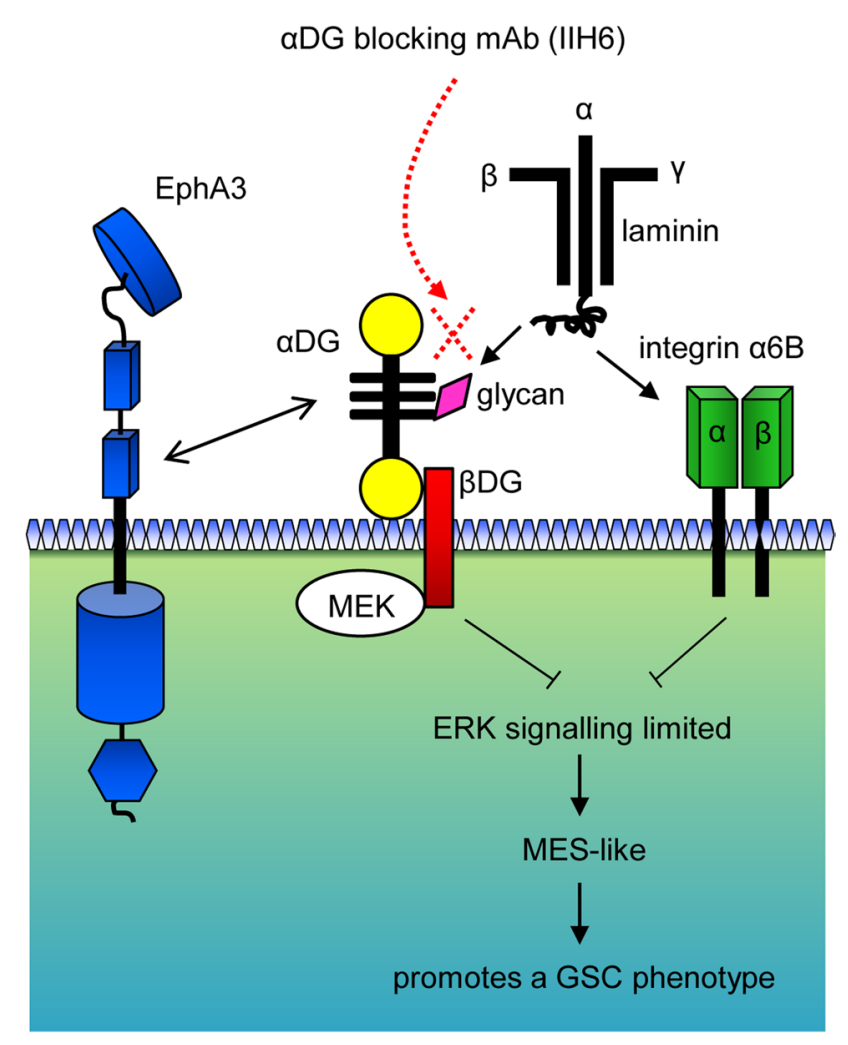

Fig. 7 The dystroglycan complex supresses MAPK activation to regulate glioma Stem cell commitment. DG, when bound to laminin, cooperates with EphA3 and integrin $\alpha 6 \mathrm{~B}$ in the vascular niche to maintain a GSC mesenchymal phenotype. Functionally, DG and integrin $\alpha 6 \mathrm{~B}$ limit sustained ERK activation preventing GSC differentiation. Blockade of $\alpha$ DG glycosylation sites, using the IIH6 $\mathrm{mAb}$, induced sustained ERK1/2 activation, leading to translocation of ERKs to the nucleus followed by GSC differentiation and reduced GBM aggressiveness

Reduction or loss of DG expression has been reported in several epithelial tumours such as breast, colon, and prostate cancers, implicating the receptor in tumour invasion and dissemination $[30,55]$. A potential mechanism to explain this phenomenon is degradation of $\beta D G$ by MMPs in the TME [33]. Additionally, defects in $\alpha$ DG glycosylation may also play a role in cancer progression. A number of cancers of epithelial origin show an association between loss of $\alpha \mathrm{DG}$ glycosylation and tumour progression. A report of this mechanism has also been shown for GBM [1]. Among several $\alpha$ DG glycosylation related genes, $L A R G E$ may have a great impact on cancer biology and the silencing of $L A R G E$ promotes cancer cell migration and anchorage-dependent growth [15, 21]. Contrary to these studies, our findings indicate that glycosylated $\alpha$ DG maintains a robust MES-like phenotype likely by promoting interaction with BM proteins in the TME and further acts to anchor GSCs within the vascular niche. Given the significant heterogeneity present in GBM, both 
mechanisms are likely true, where $\alpha \mathrm{DG}$ glycosylation is tuned to maintain MES-like or GSC states, as tumour cells exit these niches, $\alpha \mathrm{DG}$ expression is lost and tumour cell differentiation and state change occurs.

Acknowledgements We acknowledge A/Prof Fares Al-Ejeh, QIMR Berghofer for bioinformatics support. The QIMR Berghofer flow cytometry, histology and animal facilities for their assistance and expertise in enabling us to complete this study.

Author contributions BWD, JDL, KPLB, JNR, TGJ, KPC, and AWB designed the experiments, analysed the data and wrote the manuscript with contributions from all authors BWD, ZCB, KSE, YCL, RCJD, UB, SA, CO, YL, FMS, CLRJ, PI, ZL, and PRJ performed the experiments and assisted in manuscript preparation BWD and BWS generated and characterised models used in this study TR performed pathology diagnosis of brain cancer specimens RLJ coordinated patient consent and provided brain cancer specimens for analysis.

Funding This study has been supported by NHMRC grant application I.D.1078893, Cancer Council QLD and generous donations from the Sid Faithfull Family, Cure Brain Cancer Foundation and by a Paul D. Wellstone Muscular Dystrophy Cooperative Research Center Grant (1U54NS053672 to KPC). KPC is an investigator of the Howard Hughes Medical Institute. TGJ is a Principal Research Fellow with the NHMRC.

Data availability Primary GBM cell line characterisation data is publicly available from Q-Cell QIMR Berghofer https://www.qimrbergho fer.edu.au/q-cell/.

\section{Compliance with ethical standards}

Conflict of interest The authors declare no competing interests.

Informed consent Consent to utilise de-identified information from human brain cancer specimens were obtained through a Patient Information Consent Form (PICF) detailed in the Project Outline 29,917 for HREC/17/QRBW/577: Novel Therapies for Brain Cancer.

Ethical standards Human brain cancer specimens were collected from the Royal Brisbane and Women's Hospital (RBWH) under Human Ethics approved project HREC/17/QRBW/577: Novel Therapies for Brain Cancer. All mice experiments were performed according to the National Health and Medical Research Council (2013) Australian code for the care and use of animals for scientific purposes, under experimental protocols approved by the QIMR Berghofer Animal Ethics Committee.

Open Access This article is distributed under the terms of the Creative Commons Attribution 4.0 International License (http://creativeco mmons.org/licenses/by/4.0/), which permits unrestricted use, distribution, and reproduction in any medium, provided you give appropriate credit to the original author(s) and the source, provide a link to the Creative Commons license, and indicate if changes were made.

\section{References}

1. Akhavan A, Griffith OL, Soroceanu L, Leonoudakis D, LucianiTorres MG, Daemen A (2012) Loss of cell-surface laminin anchoring promotes tumor growth and is associated with poor clinical outcomes. Cancer Res 72:2578-2588. https://doi. org/10.1158/0008-5472.CAN-11-3732

2. Aranmolate A, Tse N, Colognato H (2017) Myelination is delayed during postnatal brain development in the mdx mouse model of Duchenne muscular dystrophy. BMC Neurosci 18:63. https://doi. org/10.1186/s12868-017-0381-0

3. Bao S, Wu Q, Sathornsumetee S, Hao Y, Li Z, Hjelmeland AB (2006) Stem cell-like glioma cells promote tumor angiogenesis through vascular endothelial growth factor. Cancer Res 66:7843-7848

4. Baumgartner U, Berger F, Hashemi Gheinani A, Burgener SS, Monastyrskaya K, Vassella E (2018) miR-19b enhances proliferation and apoptosis resistance via the EGFR signaling pathway by targeting PP2A and BIM in non-small cell lung cancer. Mol Cancer 17:44. https://doi.org/10.1186/s12943-018-0781-5

5. Bhat KPL, Balasubramaniyan V, Vaillant B, Ezhilarasan R, Hummelink K, Hollingsworth F et al (2013) Mesenchymal differentiation mediated by NF-kappaB promotes radiation resistance in glioblastoma. Cancer Cell 24:331-346. https://doi.org/10.1016/j. ccr.2013.08.001

6. Biernat W, Aguzzi A, Sure U, Grant JW, Kleihues P, Hegi ME (1995) Identical mutations of the p53 tumor suppressor gene in the gliomatous and the sarcomatous components of gliosarcomas suggest a common origin from glial cells. J Neuropathol Exp Neurol $54: 651-656$

7. Boyd AW, Lackmann M (2001) Signals from Eph and ephrin proteins: a developmental tool kit. Science STKE 2001: RE20-26

8. Brennan C, Momota H, Hambardzumyan D, Ozawa T, Tandon A, Pedraza A (2009) Glioblastoma subclasses can be defined by activity among signal transduction pathways and associated genomic alterations. PLoS ONE 4:e7752. https://doi.org/10.1371/ journal.pone.0007752

9. Calabrese C, Poppleton H, Kocak M, Hogg TL, Fuller C, Hamner B et al (2007) A perivascular niche for brain tumor stem cells. Cancer Cell 11:69-82

10. Calogero A, Pavoni E, Gramaglia T, D’Amati G, Ragona G, Brancaccio A (2006) Altered expression of alpha-dystroglycan subunit in human gliomas. Cancer Biol Ther 5:441-448

11. Cheng L, Huang Z, Zhou W, Wu Q, Donnola S, Liu JK et al (2013) Glioblastoma stem cells generate vascular pericytes to support vessel function and tumor growth. Cell 153:139-152. https:// doi.org/10.1016/j.cell.2013.02.021

12. Colognato H, Galvin J, Wang Z, Relucio J, Nguyen T, Harrison D (2007) Identification of dystroglycan as a second laminin receptor in oligodendrocytes, with a role in myelination. Development 134:1723-1736. https://doi.org/10.1242/dev.02819

13. Day BW, Stringer BW, Al-Ejeh F, Ting MJ, Wilson J, Ensbey KS et al (2013) EphA3 maintains tumorigenicity and is a therapeutic target in glioblastoma multiforme. Cancer Cell 23:238-248. https ://doi.org/10.1016/j.ccr.2013.01.007

14. Day BW, Stringer BW, Wilson J, Jeffree RL, Jamieson PJ, Ensbey KS et al (2013) Glioma Surgical Aspirate: A Viable Source of Tumor Tissue for Experimental Research. Cancers 5:357-371. https://doi.org/10.3390/cancers5020357

15. de Bernabe DB, Inamori K, Yoshida-Moriguchi T, Weydert CJ, Harper HA, Willer T (2009) Loss of alpha-dystroglycan laminin binding in epithelium-derived cancers is caused by silencing of LARGE. J Biol Chem 284:11279-11284. https://doi.org/10.1074/ jbc.C900007200 
16. Deschenes-Simard X, Kottakis F, Meloche S, Ferbeyre G (2014) ERKs in cancer: friends or foes? Cancer Res 74:412-419. https:// doi.org/10.1158/0008-5472.CAN-13-2381

17. Ervasti JM, Campbell KP (1993) Dystrophin-associated glycoproteins: their possible roles in the pathogenesis of Duchenne muscular dystrophy. Mol Cell Biol Hum Dis Ser 3:139-166

18. Ervasti JM, Campbell KP (1993) Dystrophin and the membrane skeleton. Curr Opin Cell Biol 5:82-87

19. Ervasti JM, Campbell KP (1991) Membrane organization of the dystrophin-glycoprotein complex. Cell 66:1121-1131

20. Ervasti JM, Ohlendieck K, Kahl SD, Gaver MG, Campbell KP (1990) Deficiency of a glycoprotein component of the dystrophin complex in dystrophic muscle. Nature 345:315-319. https://doi. org $/ 10.1038 / 345315 \mathrm{a} 0$

21. Esser AK, Miller MR, Huang Q, Meier MM, Beltran-Valero de Bernabe D, Stipp CS et al (2013) Loss of LARGE2 disrupts functional glycosylation of alpha-dystroglycan in prostate cancer. J Biol Chem 288:2132-2142. https://doi.org/10.1074/jbc. M112.432807

22. Eyermann C, Czaplinski K, Colognato H (2012) Dystroglycan promotes filopodial formation and process branching in differentiating oligodendroglia. J Neurochem 120:928-947. https://doi. org/10.1111/j.1471-4159.2011.07600.x

23. Ferletta M, Kikkawa Y, Yu H, Talts JF, Durbeej M, Sonnenberg A (2003) Opposing roles of integrin alpha6Abeta1 and dystroglycan in laminin-mediated extracellular signal-regulated kinase activation. Mol Biol Cell 14:2088-2103. https://doi.org/10.1091/mbc. E03-01-0852

24. Ferluga S, Tome CM, Herpai DM, D’Agostino R, Debinski W (2016) Simultaneous targeting of Eph receptors in glioblastoma. Oncotarget 7:59860-59876. https://doi.org/10.18632/oncotarget .10978

25. Gilbertson RJ, Rich JN (2007) Making a tumour's bed: glioblastoma stem cells and the vascular niche. Nat Rev Cancer 7:733-736

26. Goel HL, Gritsko T, Pursell B, Chang C, Shultz LD, Greiner DL (2014) Regulated splicing of the alpha6 integrin cytoplasmic domain determines the fate of breast cancer stem cells. Cell reports 7:747-761. https://doi.org/10.1016/j.celrep.2014.03.059

27. Grant JW, Steart PV, Aguzzi A, Jones DB, Gallagher PJ (1989) Gliosarcoma: an immunohistochemical study. Acta Neuropathol 79:305-309

28. Hanahan D, Weinberg RA (2011) Hallmarks of cancer: the next generation. Cell 144:646-674. https://doi.org/10.1016/j. cell.2011.02.013

29. Hawkins BT, Gu YH, Izawa Y, Del Zoppo GJ (2013) Disruption of dystroglycan-laminin interactions modulates water uptake by astrocytes. Brain Res 1503:89-96. https://doi.org/10.1016/j.brain res.2013.01.049

30. Henry MD, Campbell KP (1998) A role for dystroglycan in basement membrane assembly. Cell 95:859-870

31. Holder N, Klein R (1999) Eph receptors and ephrins: effectors of morphogenesis. Development 126:2033-2044

32. Ibraghimov-Beskrovnaya O, Ervasti JM, Leveille CJ, Slaughter CA, Sernett SW, Campbell KP (1992) Primary structure of dystrophin-associated glycoproteins linking dystrophin to the extracellular matrix. Nature 355:696-702. https://doi.org/10.1038/35569 $6 \mathrm{a} 0$

33. Jing J, Lien CF, Sharma S, Rice J, Brennan PA, Gorecki DC (2004) Aberrant expression, processing and degradation of dystroglycan in squamous cell carcinomas. Eur J Cancer 40:2143-2151. https://doi.org/10.1016/j.ejca.2004.05.018

34. Lathia JD, Gallagher J, Heddleston JM, Wang J, Eyler CE, Macswords $J$ et al (2010) Integrin alpha 6 regulates glioblastoma stem cells. Cell Stem Cell 6:421-432. https://doi.org/10.1016/j. stem.2010.02.018
35. Leiton CV, Aranmolate A, Eyermann C, Menezes MJ, EscobarHoyos LF, Husain S (2015) Laminin promotes metalloproteinasemediated dystroglycan processing to regulate oligodendrocyte progenitor cell proliferation. J Neurochem 135:522-538. https:// doi.org/10.1111/jnc. 13241

36. Louis DN, Perry A, Reifenberger G, von Deimling A, Figarella-Branger D, Cavenee WK (2016) The 2016 World Health Organization Classification of tumors of the central nervous system: a summary. Acta Neuropathol 131:803-820. https://doi. org/10.1007/s00401-016-1545-1

37. Lun M, Lok E, Gautam S, Wu E, Wong ET (2011) The natural history of extracranial metastasis from glioblastoma multiforme. J Neurooncol 105:261-273. https://doi.org/10.1007/s1106 0-011-0575-8

38. Marshall CJ (1995) Specificity of receptor tyrosine kinase signaling: transient versus sustained extracellular signal-regulated kinase activation. Cell 80:179-185

39. McClenahan FK, Sharma H, Shan X, Eyermann C, Colognato H (2016) Dystroglycan suppresses notch to regulate stem cell niche structure and function in the developing postnatal subventricular zone. Dev Cell 38:548-566. https://doi.org/10.1016/j.devce 1.2016.07.017

40. McDearmon EL, Combs AC, Sekiguchi K, Fujiwara H, Ervasti JM (2006) Brain alpha-dystroglycan displays unique glycoepitopes and preferential binding to laminin-10/11. FEBS Lett 580:33813385. https://doi.org/10.1016/j.febslet.2006.05.010

41. Menezes MJ, McClenahan FK, Leiton CV, Aranmolate A, Shan X, Colognato H (2014) The extracellular matrix protein laminin alpha2 regulates the maturation and function of the blood-brain barrier. J Neurosci 34:15260-15280. https://doi.org/10.1523/ JNEUROSCI.3678-13.2014

42. Michele DE, Barresi R, Kanagawa M, Saito F, Cohn RD, Satz JS et al (2002) Post-translational disruption of dystroglycan-ligand interactions in congenital muscular dystrophies. Nature 418:417422. https://doi.org/10.1038/nature00837

43. Moore SA, Saito F, Chen J, Michele DE, Henry MD, Messing A et al (2002) Deletion of brain dystroglycan recapitulates aspects of congenital muscular dystrophy. Nature 418:422-425. https:// doi.org/10.1038/nature00838

44. Myshrall TD, Moore SA, Ostendorf AP, Satz JS, Kowalczyk T, Nguyen H (2012) Dystroglycan on radial glia end feet is required for pial basement membrane integrity and columnar organization of the developing cerebral cortex. J Neuropathol Exp Neurol 71:1047-1063. https://doi.org/10.1097/NEN.0b013e318274a128

45. Nagaishi M, Paulus W, Brokinkel B, Vital A, Tanaka Y, Nakazato Y (2012) Transcriptional factors for epithelial-mesenchymal transition are associated with mesenchymal differentiation in gliosarcoma. Brain Pathol 22:670-676. https://doi.org/10.111 1/j.1750-3639.2012.00571.x

46. Neftel C, Laffy J, Filbin MG, Hara T, Shore ME, Rahme GJ et al (2019) an integrative model of cellular states, plasticity, and genetics for glioblastoma. Cell 178(835-849):e821. https://doi. org/10.1016/j.cell.2019.06.024

47. Nico B, Tamma R, Annese T, Mangieri D, De Luca A, Corsi $P$ et al (2010) Glial dystrophin-associated proteins, laminin and agrin, are downregulated in the brain of mdx mouse. Lab Invest 90:1645-1660. https://doi.org/10.1038/labinvest.2010.149

48. Noell S, Wolburg-Buchholz K, Mack AF, Beedle AM, Satz JS, Campbell KP (2011) Evidence for a role of dystroglycan regulating the membrane architecture of astroglial endfeet. Eur J Neurosci 33:2179-2186. https://doi.org/10.1111/j.1460-9568.2011.07688.x

49. Noell S, Wolburg-Buchholz K, Mack AF, Ritz R, Tatagiba M, Beschorner R (2012) Dynamics of expression patterns of AQP4, dystroglycan, agrin and matrix metalloproteinases in human glioblastoma. Cell Tissue Res 347:429-441. https://doi.org/10.1007/ s00441-011-1321-4 
50. Offenhauser C, Al-Ejeh F, Puttick S, Ensbey KS, Bruce ZC, Jamieson PR, Smith FM, et al. (2018) EphA3 pay-loaded antibody therapeutics for the treatment of glioblastoma. Cancers (Basel) 10(12): 519. https://doi.org/10.3390/cancers 10120519

51. Pasquale EB (2010) Eph receptors and ephrins in cancer: bidirectional signalling and beyond. Nat Rev Cancer 10:165-180. https ://doi.org/10.1038/nrc2806

52. Pollard SM, Yoshikawa K, Clarke ID, Danovi D, Stricker S, Russell R et al (2009) Glioma stem cell lines expanded in adherent culture have tumor-specific phenotypes and are suitable for chemical and genetic screens. Cell Stem Cell 4:568-580. https://doi. org/10.1016/j.stem.2009.03.014

53. Prochazka M, Gaskins HR, Shultz LD, Leiter EH (1992) The nonobese diabetic scid mouse: model for spontaneous thymomagenesis associated with immunodeficiency. Proc Natl Acad Sci USA 89:3290-3294

54. Qazi MA, Vora P, Venugopal C, Adams J, Singh M, Hu A et al (2018) Cotargeting ephrin receptor tyrosine kinases A2 and A3 in cancer stem cells reduces growth of recurrent glioblastoma. Cancer Res 78:5023-5037. https://doi.org/10.1158/0008-5472. CAN-18-0267

55. Sgambato A, Migaldi M, Montanari M, Camerini A, Brancaccio A, Rossi G et al (2003) Dystroglycan expression is frequently reduced in human breast and colon cancers and is associated with tumor progression. Am J Pathol 162:849-860. https://doi. org/10.1016/S0002-9440(10)63881-3

56. Spence HJ, Dhillon AS, James M, Winder SJ (2004) Dystroglycan, a scaffold for the ERK-MAP kinase cascade. EMBO Rep 5:484-489. https://doi.org/10.1038/sj.embor.7400140

57. Stringer BW, Day BW, D'Souza RCJ, Jamieson PR, Ensbey KS, Bruce ZC et al (2019) A reference collection of patient-derived cell line and xenograft models of proneural, classical and mesenchymal glioblastoma. Sci Rep 9(1):4902. https://doi.org/10.1038/ s41598-019-41277-z
58. Vail ME, Murone C, Tan A, Hii L, Abebe D, Janes PW et al (2014) Targeting EphA3 inhibits cancer growth by disrupting the tumor stromal microenvironment. Cancer Res 74:4470-4481. https://doi. org/10.1158/0008-5472.CAN-14-0218

59. Verhaak RG, Hoadley KA, Purdom E, Wang V, Qi Y, Wilkerson MD et al (2010) Integrated genomic analysis identifies clinically relevant subtypes of glioblastoma characterized by abnormalities in PDGFRA, IDH1, EGFR, and NF1. Cancer Cell 17:98-110. https://doi.org/10.1016/j.ccr.2009.12.020

60. Wang Q, Hu B, Hu X, Kim H, Squatrito M, Scarpace L et al (2017) Tumor evolution of glioma-intrinsic gene expression subtypes associates with immunological changes in the microenvironment. Cancer Cell 32(42-56):e46. https://doi.org/10.1016/j.ccell .2017 .06 .003

61. Wei J, Shaw LM, Mercurio AM (1998) Regulation of mitogenactivated protein kinase activation by the cytoplasmic domain of the alpha6 integrin subunit. J Biol Chem 273:5903-5907

62. Xie Y, Bergstrom T, Jiang Y, Johansson P, Marinescu VD, Lindberg $\mathrm{N}$ et al (2015) The human glioblastoma cell culture resource: validated cell models representing all molecular subtypes. EBioMedicine 2:1351-1363. https://doi.org/10.1016/j. ebiom.2015.08.026

63. Yoneyama T, Angata K, Bao X, Courtneidge S, Chanda SK, Fukuda M (2012) Fer kinase regulates cell migration through alpha-dystroglycan glycosylation. Mol Biol Cell 23:771-780. https://doi.org/10.1091/mbc.E11-06-0517

Publisher's Note Springer Nature remains neutral with regard to jurisdictional claims in published maps and institutional affiliations. 